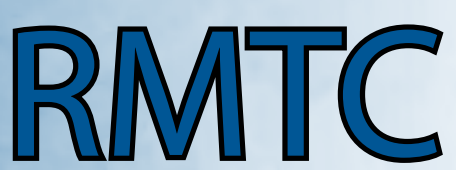

Relevé des maladies transmissibles au Canada

ISSN $1188-4169$

Volume : 3652

Janvier 2010

\title{
Supplément
}

\section{CONSEIL POUR CONSIDÉRATION DU VACCIN CONJUGUÉ QUADRIVALENT CONTRE LE MÉNINGOCOQUE (A, C, Y, W135) POUR UTILISATION PAR LES PROVINCES ET TERRITOIRES}

Comité canadien d'immunisation 


\section{Remerciements}

Le Centre de l'immunisation et des maladies respiratoires infectieuses de l'Agence de la santé publique du Canada, par le biais d'un contrat avec le Dr Philippe De Wals de l'unité de recherche en santé publique du Centre de recherche de l'Hôpital de l'université du Québec, a demandé une évaluation du vaccin quadrivalent contre le méningocoque au moyen du cadre analytique Erickson, De Wals et Farand. Le présent rapport s'appuie principalement sur l'évaluation fournie par le Dr De Wals et représente les informations épidémiologiques et économiques disponibles en septembre 2007. Les renseignements sur le fardeau de la maladie et sur les caractéristiques du vaccin ont été mis à jour dans une déclaration du Comité consultatif national de l'immunisation (CCNI) en 2009.

Nous tenons à remercier le Dr De Wals pour son étude scientifique, son analyse critique et son opinion d'expert.

\section{Citation suggérée :}

Comité canadien d'immunisation et l'Agence de la santé publique du Canada Conseil pour considération du vaccin conjugé quadrivalent contre le méningocoque $(A, C, Y, W 135)$ pour utilisation par les provinces et territoires

RMTC 2009

On peut aussi avoir accès électroniquement à cette publication par Internet en utilisant un explorateur Web à :

http://www.phac-aspc.gc.ca 


\section{CONSEIL POUR CONSIDÉRATION DU VACCIN CONJUGUÉ QUADRIVALENT CONTRE LE MÉNINGOCOQUE (A, C, Y, W135) POUR UTILISATION PAR LES PROVINCES ET TERRITOIRES}




\section{Table des matières}

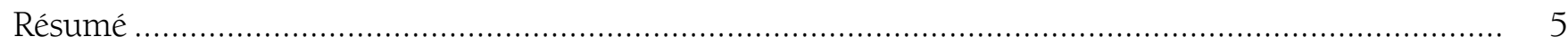

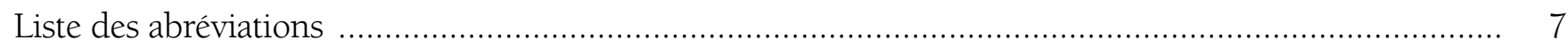

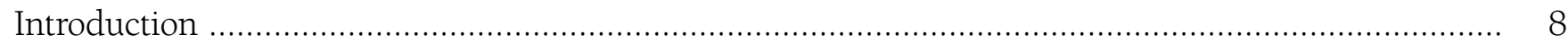

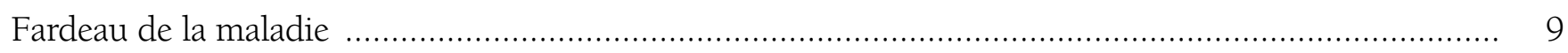

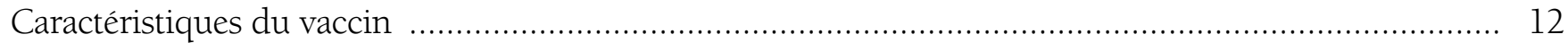

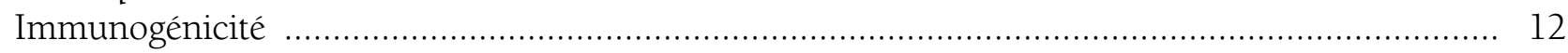

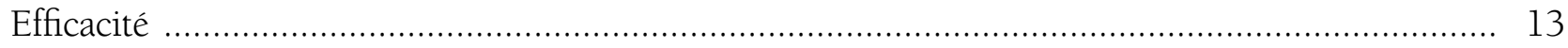

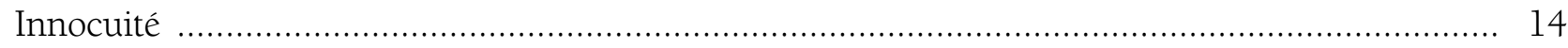

Administration concommitante du vaccin .................................................................. 15

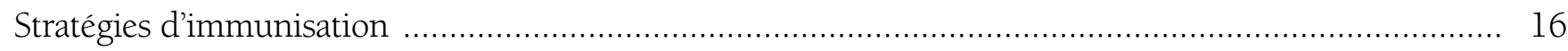

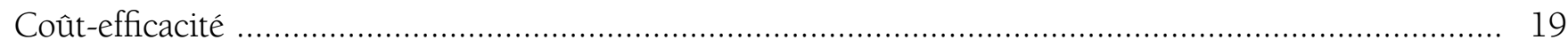

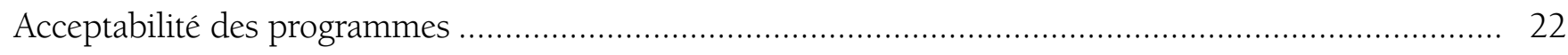

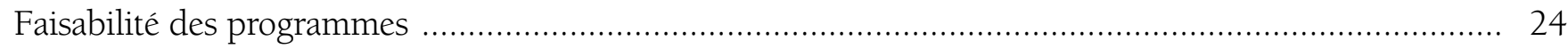

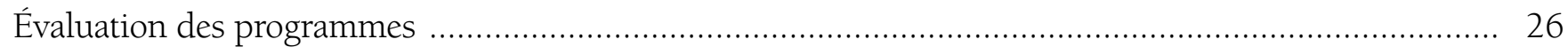

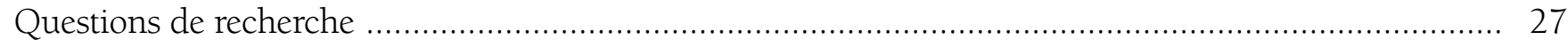

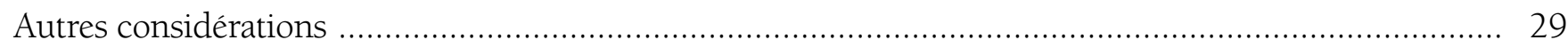

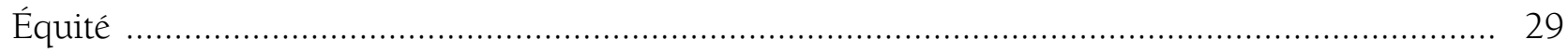

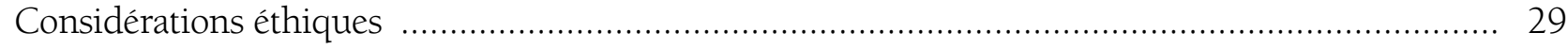

Conseils du CCI sur l'emploi préventif des vaccins antiméningococciques ............................ 29

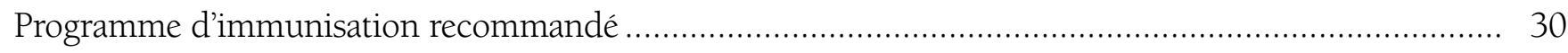

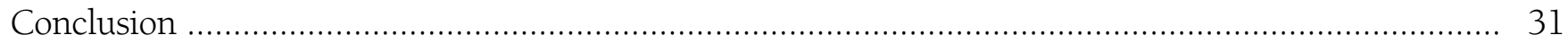

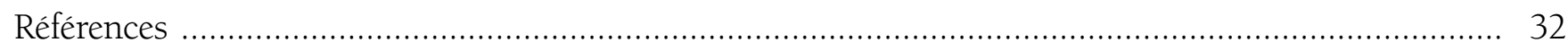




\section{Liste des figures}

Figure 1 : Risque par groupe d'âge de méningococcie invasive évitable par la vaccination au Canada (De Wals et coll., 2007).

\section{Liste des tableaux}

Tableau 1 : Recommandations concernant le calendrier d'immunisation contre la méningococcie invasive du sérogroupe C dans les provinces et territoires canadiens (ASPC 2007/12/28)

Tableau 2: Coût estimé des programmes pour le système de santé, selon différentes couvertures des populations d'adolescents avec un vaccin méningococcique conjugué quadrivalent au Canada

Tableau 3 : Coût-efficacité de différentes stratégies d'immunisation en utilisant le vaccin méningococcique conjugué du sérogroupe $\mathrm{C}$ (MenC-C) ou le vaccin méningococcique conjugué quadrivalent (Men4-DT) chez une population d'un million de personnes au Canada, dans un scénario modèle de base (De Wals et coll., 2007)

Tableau 4 : Programmes de vaccination pour les jeunes de 9 à 16 ans dans les provinces et territoires canadiens (ASPC 2007b) 
En 2006, le Canada autorisait l'utilisation du premier vaccin conjugué quadrivalent contre le méningocoque (Menactra ${ }^{\mathrm{MC}}$ ). La présente déclaration fournit une analyse reposant sur des données probantes; celle-ci est nécessaire à la prise en considération de ce vaccin dans la planification des programmes de vaccination provinciaux et territoriaux. Les provinces et territoires sont responsables de la prestation des programmes de vaccination et prendront en compte leurs propres circonstances dans la prise de décisions au sujet du vaccin à partir de l'analyse critique présentée dans ce rapport.

Historiquement, l'épidémiologie des atteintes méningococciques au Canada a été caractérisée par un contexte endémique et l'occurrence de grandes épidémies et d'éclosions plus modestes à intervalles irréguliers. On relève des différences marquées entre les sérogroupes, les souches du sérogroupe B causant la majorité des cas sporadiques et les clones virulents du sérogroupe C ayant causé la plupart des éclosions observées au cours des deux dernières décennies. Jusqu'à maintenant, il n'a pas été possible de prédire de façon fiable l'épidémiologie des atteintes méningococciques, de sorte que la possibilité de l'occurrence de nouvelles épidémies ou éclosions causées par les clones virulents de tout sérotype ne peut être exclue au Canada.

Dans tous les essais existants auprès de personnes de deux ans ou plus, la réponse immunologique à court terme à Menactra ${ }^{\mathrm{MC}}$ n'était pas inférieure à la réponse au vaccin polysaccharidique quadrivalent. Menactra ${ }^{\mathrm{MC}}$ a généré des anticorps ayant de meilleures caractéristiques fonctionnelles et une plus longue persistance, tout en induisant une forte réponse anamnestique par suite d'une injection de rappel sans hyporéactivité. Par conséquent, on devrait accorder la préférence à
Menactra ${ }^{\mathrm{MC}}$ plutôt qu'au vaccin polysaccharidique quadrivalent pour toutes les indications d'un vaccin méningococcique quadrivalent ou d'un sérogroupe A, Y ou W135 chez les 2 ans et plus. L'efficacité sur le terrain des vaccins conjugués monovalents du sérogroupe $C$ a été évaluée dans de grandes études épidémiologiques faisant suite à leur mise en marché. Présentement, on ne dispose d'aucunes données sur l'efficacité clinique de Menactra ${ }^{\mathrm{MC}}$. On n'a fait aucune étude immunologique présentant une comparaison point par point entre Menactra ${ }^{\mathrm{MC}}$ et les vaccins conjugués du sérogroupe $C$ mis à l'essai sur le terrain contenant le dérivé de protéine comme porteur CRM197 à l'anatoxine diphtérique (Meningitec $^{\mathrm{MC}}$ et Menjugate ${ }^{\mathrm{MC}}$ ) ou à l'anatoxine tétanique (Neis Vac- $\mathrm{C}^{\mathrm{MC}}$ ). Bien que la réponse immunitaire de Menactra ${ }^{\mathrm{MC}}$ ait été comparée à la réponse au vaccin polysaccharidique et ait été jugée non inférieure pour le sérogroupe $C$, on a établi que le vaccin polysaccharidique fournit un faible niveau de protection de courte durée contre ce sérogroupe chez les enfants. Pour ces raisons, tant que de nouvelles études ne seront disponibles, les vaccins conjugués monovalents contre le sérogroupe $\mathrm{C}$ devraient être préférés pour toutes les indications d'immunisation contre les atteintes méningococciques du sérogroupe C, surtout chez les enfants. Alors que l'efficacité des vaccins polysaccharidiques dans la prévention des méningococcies invasives (MI) de sérogroupe A et C a été clairement démontrée dans les études expérimentales et par observation chez les adolescents et les adultes, les études immunologiques ont démontré que Menactra ${ }^{\mathrm{MC}}$ (Men4-DT) est un vaccin plus puissant. Pour cette raison, Men4-DT pourrait être considéré pour l'immunisation systématique des adolescents, y compris de ceux déjà immunisés en bas âge au moyen d'un vaccin conjugué monovalent contre le sérogroupe C. 
L'expérience de l'administration de Menactra ${ }^{\mathrm{MC}}$ dans neuf études cliniques comptant plus de 10000 sujets participants est très rassurante puisque les événements négatifs observés n'étaient pas différents de ceux signalés dans les groupes de contrôle auxquels on a administré un vaccin polysaccharidique quadrivalent. Aux États-Unis, Menactra ${ }^{\mathrm{MC}}$ est utilisé pour vacciner les adolescents et les collégiens. En date du 25 février 2008, plus de 15 millions de doses de Menactra avaient été distribuées et le système VAERS (Vaccine Adverse Event Reporting Systems) avait reçu 26 rapports de cas confirmés de streptocoque du groupe B (SGB) dans les 6 semaines suivant la réception du vaccin méningococcique Menactra ${ }^{\mathrm{MC}}$. Une relation causale n'a pas été établie, mais l'existence d'un risque de très petite magnitude ne peut être exclue. Au Canada, l'indication préférée du Menactra ${ }^{\mathrm{MC}}$ est pour la vaccination des adolescents à l'âge de 12 ans, soit juste avant l'augmentation de l'incidence de la méningococcie qui survient à l'âge de 13 ans. Pour les adolescents non vaccinés auparavant, il s'agirait d'une vaccination primaire et, pour les sujets déjà vacciné d'un vaccin conjugué monovalent contre le sérogroupe $C$ en bas âge, il s'agirait d'une injection de rappel contre le sérogroupe $C$ et d'une vaccination primaire contre les sérogroupes A, Y et W135. La vaccination d'une importante proportion d'adolescents pourrait réduire considérablement la transmission des souches pathogènes dans toute la population, puisque la prévalence des porteurs de $N$. meningitidis est maximale dans ce groupe d'âges.

En calculant le prix d'achat du vaccin à $70 \$$ la dose de Menactra ${ }^{\mathrm{MC}}$, les coûts d'un programme annuel pour les adolescents se situeraient entre 19 et 29 millions de dollars au Canada. Un modèle de simulation a été élaboré afin d'évaluer les effets directs et indirects d'une injection de rappel à l'âge de 12 ans avec, soit un vaccin monovalent $C$, soit un vaccin conjugué quadrivalent contre le méningocoque ACYW135 dans une cohorte de Canadiens immunisés à 12 mois avec un vaccin conjugué monovalent C (23 \$/dose). La revaccination à 12 ans au moyen d'un vaccin contre le sérogroupe $C$ réduirait le fardeau de la maladie de 55\% sans coût marginal (on prévoit plutôt une légère économie). L'utilisation de Menactra $^{\mathrm{MC}}$ comme injection de rappel entraînerait une réduction de la maladie de 78 \% à un coût marginal de 31000 \$ par AVAQ gagnée comparativement à une dose de vaccin contre le sérogroupe C à 12 mois. Quand on compare Menactra ${ }^{\mathrm{MC}}$ avec le vaccin contre le sérogroupe C comme injection de rappel, le ratio de coûtefficacité serait de 113000 \$ par AVAQ.

La méningococcie compte parmi les maladies les plus craintes, de sorte que l'inclusion d'un nouveau vaccin dans le calendrier de vaccination régulier des adolescents serait bien reçue par la majorité de la population et des professionnels de la santé.

Idéalement, la vaccination contre la méningococcie durant l'adolescence devrait être administrée à 12 ans, dans le cadre d'un programme dans les écoles ( $7^{\mathrm{e}}$ année), et combinée à d'autres vaccinations. La décision d'utiliser Menactra ${ }^{\mathrm{MC}}$ ou un produit monovalent contre le sérogroupe $C$, est du ressort des provinces/territoires dans l'allocation des ressources. 


\section{Liste des abréviations}

MI : méningococcie invasive

Men4-DT : vaccin quadrivalent contre le méningocoque (sérogroupes A, C, W135 et Y) à polysaccharide conjugué à une anatoxine diphtérique comme vecteur protéique (Menactra ${ }^{\mathrm{MC}}$ )

MenC-C : vaccin conjugué monovalent contre le sérogroupe C du méningocoque 


\section{Introduction}

En 2006, un premier vaccin conjugué quadrivalent contre le méningocoque (Menactra ${ }^{\mathrm{MC}}$ ) fut autorisé au Canada (Sanofi Pasteur ltée, 2006) et le Comité consultatif national de l'immunisation a publié une déclaration sur l'utilisation de ce vaccin, axée sur les résultats des études d'immunogénicité et d'innocuité, fournissant des indications et recommandations à l'égard de son administration (CCNI, 2007). Le présent rapport vise à fournir une évaluation complète de l'utilité potentielle d'un vaccin conjugué quadrivalent contre le méningocoque dans le contexte canadien au moyen du cadre analytique proposé par Erickson et coll., (2005) et à formuler des recommandations quant à l'utilisation du vaccin Menactra ${ }^{\mathrm{MC}}$ dans les programmes de prévention de la méningococcie invasive subventionnés par l'État au Canada. 


\section{Fardeau de la maladie}

Historiquement, l'épidémiologie de la MI au Canada a été caractérisée par un contexte endémique et l'occurrence de grandes épidémies et d'éclosions plus modestes à intervalles irréguliers. Lépidémiologie de la MI au cours de la période 1995 à 2004 a récemment été étudiée par le Comité consultatif national de l'immunisation (2007). Le taux global annuel d'incidence a varié entre 0,6 et 1,1 par 100,000, avec une moyenne de 244 cas de MI déclarés et un taux de mortalité des cas de $9 \%$. On a relevé des différences marquées entre les sérogroupes.

Le sérogroupe B était responsable de la majorité des cas sporadiques et de $44 \%$ des cas relevés chez les enfants de moins de 5 ans (l'âge médian des cas $=11$ ans), le taux de létalité des cas était de $6 \%$. La majorité des cas furent causés par des méningocoques de diversité génétique et phénotypique considérable (Ashton et coll., 2001). Présentement, il n'existe aucun vaccin contre le sérogroupe B circulant au Canada ou en Amérique du Nord (Girard et coll., 2006).

Au cours des 20 dernières années, plusieurs éclosions ont été causées par des souches virulentes du sérogroupe C caractérisées par l'antigène de sérotype 2 a et appartenant au complexe clonal de type électro phorétique 15 (Law et coll., 2005). De 1995 à 2004, le nombre annuel moyen de cas signalés du sérogroupe $C$ était de 84 . Au cours de cette période, on a observé une baisse progressive de l'incidence des cas du sérogroupe C. Cette baisse pourrait s'expliquer en partie par les campagnes de vaccination massive et les programmes de vaccination systématique mis en œuvre par les provinces et territoires depuis 2000. La distribution par âge des cas de MI du sérogroupe C est bimodale, le plus fort taux d'incidence se situant autour de 18 ans et la seconde pointe survenant vers l'âge d'un an (âge médian des cas = 19 ans). La
MI causée par les clones épidémiques du sérogroupe C fut particulièrement sévère, présentant une forte proportion de cas de septicémie fulminante, surtout chez les adolescents et les jeunes adultes, un taux de létalité de l'ordre de $12-14$ \% et une proportion semblable de survivants présentant des séquelles physiques permanentes (Erickson et coll., 1998).

Le sérogroupe Y a été une cause de cas sporadiques dont l'incidence a été relativement stable entre 1995 et 2004, le nombre moyen de cas se situant à 28 par année. Lintensification transitoire de l'incidence du sérogroupe Y observée aux É.-U. au cours des années 1990 et au début des années 2000 (Harrison et coll., 2006) ne s'est pas manifestée au Canada. Le typage génomique multilocus a dégagé deux populations clonales non apparentées de méningocoques du sérogroupe Y appartenant aux complexes clonaux ST-23 et ST-167 (Tsang et coll., 2007). Le sérogroupe Y tend à affecter les personnes plus âgées (l'âge médian des cas $=45$ ans) et le taux de létalité a été de $7 \%$.

Les souches du sérogroupe W135 n'ont pas été isolées fréquemment au cours des dernières années, une moyenne annuelle de 9 cas étant signalés. Lâge médian des cas a été de 19 ans et le taux de létalité de $8 \%$. Aucun cas provenant des souches épidémiques qui circulent dans les pays africains et arabes n'a été détecté jusqu'à maintenant.

En 1940-1943, le Canada a connu une épidémie d'envergure nationale causée par le méningocoque du sérogroupe A. Bien que ce sérogroupe soit toujours la cause de grandes épidémies en Afrique et dans d'autres parties du monde, il a rarement été isolé au cours des dernières années, entre 0 et 2 cas étant signalés annuellement. En vue d'estimer, pour chaque âge, le risque de MI évitable par la vaccination avant la mise en œuvre de programmes 
de vaccination systématiques au Canada, les données de surveillance pour la période 19952001 ont été utilisées (Deeks et coll., 1997; Squires et coll., 2000; Squires et coll., 2004), avec rajustement en fonction du sous-diagnostic lorsque le diagnostic PCR n'était pas disponible (10\% des cas de MI) (Lorange et coll., 2002), en fonction de la sous-déclaration ( $5 \%$ des cas de MI) (Rivest et coll., 1999) et en fonction des cas de MI de sérogroupes inconnus (proportion spécifique à l'année) (Deeks et coll., 1997 ; Squires et coll., 2000 ; Squires et coll., 2004). Comme le montre la figure 1 , l'incidence des cas de MI évitables par la vaccination a été dominée par le sérogroupe $C$ et le risque était à son maximum chez les personnes de 19 ans (2,3/100,000 personnes-années) et à son minimum dans le groupe d'âges de 30 à 39 ans (0,2/100,000 personnes-années). Chez les enfants, on a observé une pointe autour de l'âge d'un an, de faibles taux chez les écoliers du primaire et d'une augmentation à partir de l'âge de 13 ans. Les taux de mortalité par groupe d'âge au Canada en 1990-1992 ont été utilisés pour calculer le nombre de personnes à risque pour chaque année d'âge d'une cohorte de naissances donnée (Statistique Canada, 1996). Le risque estimé à vie de MI évitable par la vaccination était de 44 cas par 100,000, y compris 33 cas du sérogroupe C, 9 cas du sérogroupe Y, 2 cas du sérogroupe W135 et moins d'un cas du sérogroupe $\mathrm{A}$.

Figure 1 : Risque par groupe d'âge de méningococcie invasive évitable par la vaccination au Canada (De Wals et coll., 2007)

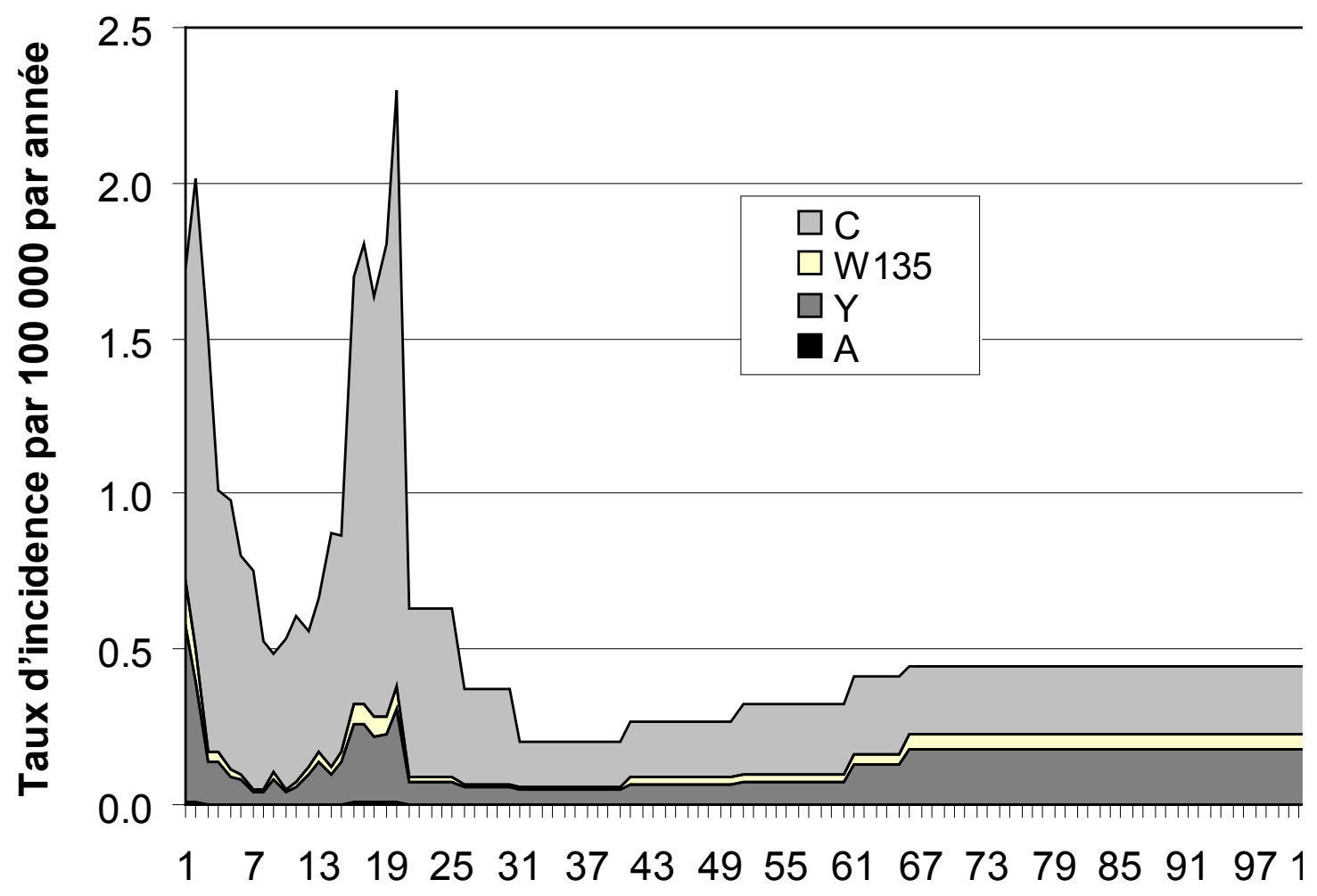

Jusqu'à maintenant, il n'a pas été possible de prédire avec certitude l'épidémiologie de la MI dans quelque partie du monde qui soit. Dans les pays industrialisés, les taux de MI endémique sont demeurés relativement stables au cours du dernier siècle et les épidémies ou éclosions ont été causées 
surtout par les méningocoques des sérogroupes A, B et C. (Rosenstein et coll., 2001; Pollard, 2004; Stephens et coll., 2007). Dans la « ceinture africaine de méningite », les épidémies sont surtout associées aux clones du sérogroupe A et, récemment, de plus petites éclosions ont été causées par de nouveaux clones des sérogroupes W135 et Y. Ces souches virulentes pourraient être importées et on ne peut exclure l'occurrence de nouvelles épidémies ou éclosions causées par des clones virulents de tout sérotype au Canada. 


\section{Caractéristiques du vaccin}

\section{Immunogénicité}

Les vaccins conjugués contre le méningocoque, comme les autres vaccins à conjugaison polysaccharide-protéine, élicitent une réponse immunologique thymodépendante déjà présente à la naissance et sont caractérisés par le développement de cellules de mémoire B et par la production d'une diversité de classes et de sous-classes d'immunoglobuline ayant une grande affinité pour l'antigène polysaccharidique capsulaire (Stein, 1992). Quel que soit le type de vaccin, l'âge à l'administration du vaccin et le nombre de doses, les concentrations d'anticorps sériques diminuent avec le temps alors que la mémoire est de longue durée (De Wals, 2006). Les mécanismes de protection fournis par les vaccins conjugués contre le méningocoque ne sont pas entièrement compris, mais on sait que les anticorps des muqueuses et sériques dirigés contre les polysaccharides capsulaires jouent un rôle majeur en liant les structures de surfaces bactériennes et par activation du complément menant à la phagocytose ou à l'extermination directe des bactéries (Pollard et coll., 2001). Lactivité bactéricide du sérum en présence d'un complément mesurée in vitro est un marqueur de protection reconnu. Dans des études aux É.-U., on a observé une corrélation inverse entre l'incidence de la méningococcie à un âge donné et la prévalence de l'activité bactéricide du sérum à un âge donné au niveau de la population (Goldschneider et coll., 1969). Dans une étude prospective chez les recrues militaires, la MI du sérogroupe $C$ survenait rarement chez les personnes ayant des titres d'activité bactéricide du sérum en circulation de $\geq 4$ (Goldschneider et coll., 1969). Des d'activité bactéricide du sérum de $\geq 4$ utilisant un complément humain ont été proposés comme marqueur de protection contre la MI du sérogroupe C et des seuils compris entre $\geq 8$ et $\geq 128$ ont été proposés pour essais utilisant des lapins comme complément (Andrews et coll., 2003; Borrow et coll., 2005). Cependant, ces seuils ne confèrent pas une protection absolue, des cas de MI du sérogroupe C ayant été observés chez des patients à titres préexistants d'activité bactéricide du sérum de $\geq 4$ utilisant un complément humain (Goldschneider et coll., 1969). De plus, des titres plus faibles ne signifient pas nécessairement la susceptibilité. Dans $25 \%$ des sérums d'adultes humains non immunisés ayant des titres d'activité bactéricide du sérum de $\geq 4$ (complément humain), des anticorps anticapsulaires à forte avidité étaient présents en concentration insuffisante pour éliciter une bactériolyse in vitro en présence d'un complément mais suffisante pour conférer la protection dans un modèle in vivo chez le rat (Welsh et coll. 2004). Pour les sérogroupes A, W135 et Y, il n'existe pas de seuil de protection établi.

Un premier vaccin conjugué quadrivalent (A, C, $\mathrm{W} 135, \mathrm{Y})$ contre le méningocoque (Menactra $\left.{ }^{\mathrm{MC}}\right)$ a été homologué au Canada en 2006 et a été approuvé pour utilisation chez les personnes de 2 à 55 ans (Sanofi Pasteur ltée 2006; CCNI 2007). Une dose de 0,5 mL de ce vaccin contient $4 \mu \mathrm{g}$ de chacun des quatre polysaccharides conjugués jusqu'à un total de $48 \mu \mathrm{g}$ de porteur de protéine d'anatoxine diphtérique. D'autres produits présentement en développement utilisent un dérivé de protéine à l'anatoxine diphtérique ou à l'anatoxine tétanique comme porteur CRM197. La réponse immunologique au vaccin conjugué quadrivalent (A, C, W135, Y) à anatoxine diphtérique contre le méningocoque (Men4-DT) a été étudiée pour différents groupes d'âges et différents marqueurs immunologiques ont été fournis dans les rapports, y compris la moyenne géométrique du titre d'activité bactéricide du sérum (lapin comme complément) au jour 28 et à 6 mois, le pourcentage de sujets ayant séroconverti (défini comme titre d'activité bactéricide du sérum de $<1: 8$ le jour 0 et de $\geq 1: 32$ le jour 28), le pourcentage de sujets ayant une augmentation de 
$\geq 4$ du titre d'activité bactéricide du sérum et le pourcentage de sujets ayant un titre d'activité bactéricide du sérum le jour 28 de $\geq 1: 128$ ou de 1:8 (Sanofi Pasteur ltée, 2006; Rennels et coll. 2002; Rennels et coll. 2004). En général, la réponse était meilleure pour le sérogroupe A que pour les autres sérogroupes et une réponse liée à lâge a aussi été observée. Chez les jeunes enfants, la proportion de sujets présentant des titres d'activité bactéricide du sérum de $\geq 1: 8$ un mois après 3 doses se situait entre $92 \%$ pour le sérogroupe A et seulement $54 \%$ pour le sérogroupe C (Rennels et coll. 2004). Chez les enfants de 12 à 22 mois, deux doses étaient nécessaires pour obtenir une réponse satisfaisante (Rennels et coll. 2002). Chez les sujets de 2-10 ans, le pourcentage de séroconversion après une dose était de $99 \%$ pour le sérogroupe A, $96 \%$ pour le sérogroupe W135, 88 \% pour le sérogroupe C et 86 \% pour le sérogroupe Y (Pichichero et coll., 2005). Dans un autre essai, la proportion de séroconversion était de 97 \% pour les sérogroupes A et W135 et 100 $\%$ pour les sérogroupes $C$ et $Y$ (Lagos et coll., 2005). Chez les enfants de 2-3 ans, Men4-DT a activé des anticorps contre le sérogroupe $C$ ayant une activité fonctionnelle plus élevée que ceux activés par le vaccin polysaccharidique quadrivalent (Granoff et coll. 2004). Pour tous les sérogroupes, cependant, les concentrations d'anticorps diminuaient avec le temps et, 2-3 ans après l'administration de Men4-DT, de nombreux sujets présentaient des titres d'activité bactéricide du sérum (complément humain) inférieurs à 1:4 (Granoff et coll., 2005). Cependant, la persistance de la mémoire immunitaire et l'absence d'hyporéactivité ont été démontrées après l'administration d'un dixième d'une dose de vaccin polysaccharidique tétravalent (Pichichero, 2005). Dans un autre essai, des enfants âgés de 2 à 4 ans, vaccinés plus d'un an auparavant au moyen d'un vaccin conjugué monovalent contre le sérogroupe $C$ reçurent une dose de Men4-DT et la réponse au sérogroupe $\mathrm{C}$ fut de grande amplitude, de l'ordre de la réponse à une injection de rappel chez des individus vaccinés une première fois (El
Bashir et coll., 2006). Chez les adolescents et les adultes, Men4-DT produisit une forte réaction immunologique accusant des taux de séroconversion dépassant $90 \%$ pour tous les sérogroupes (Sanofi Pasteur ltée, 2006). Chez les adolescents, la persistance des anticorps protecteurs et de la mémoire immunologique contre tous les sérogroupes a été démontrée jusqu'à 3 ans après l'administration d'une dose de Men4-DT (Pichichero, 2005; Vu et coll., 2006).

\section{Efficacité}

Tous les vaccins conjugués contre le méningocoque ont été homologués en fonction d'études immunologiques et de critères définis par des experts (CCNI 2007). Dans tous les essais chez des personnes de 2 ans ou plus, la réponse immunologique à court terme au Men4-DT n'était pas inférieure à la réponse au vaccin polysaccharidique quadrivalent. Men4-DT a généré des anticorps ayant de meilleures caractéristiques fonctionnelles et une plus longue persistance tout en déclenchant une forte réponse anamnestique après une injection de rappel sans hyporéactivité (Sanofi Pasteur ltée 2006; CCNI 2007). Pour toutes ces raisons, Men4-DT devrait avoir la préférence par rapport au vaccin polysaccharidique quadrivalent pour toutes les indications d'un vaccin quadrivalent ou d'un vaccin contre le méningocoque des sérogroupes $\mathrm{A}$, Y ou W135 chez les 2 ans et plus.

Lefficacité sur le terrain des vaccins conjugués monovalents contre le sérogroupe $C$ a été évaluée dans de grandes études épidémiologiques faisant suite à leur mise en marché et les résultats de ces études indiquent un degré élevé de protection au cours de la première année suivant l'immunisation primaire avec un nombre variable de doses dans tous les groupes d'âges, une protection soutenue jusqu'à 4 ans après l'administration d'une dose au cours de la deuxième année de vie ou après, mais aucune preuve 
de protection soutenue pour ceux qui ont reçu une série d'immunisations primaires avant l'âge de 6 mois (Trotter et coll., 2004; De Wals et coll., 2004; Larrauri et coll., 2005). Jusqu'à maintenant, il existe peu de preuves concernant la protection soutenue au-delà de 4 ans chez ceux qui ont reçu un vaccin conjugué monovalent contre le sérogroupe $\mathrm{C}$ au cours de la deuxième année de vie ou après. À l'heure actuelle, il n'existe aucunes données sur l'efficacité clinique de Men4-DT et aucune étude immunologique ne fournit une comparaison côte-à-côte de Men4-DT avec des vaccins conjugués éprouvés sur le terrain contre le sérogroupe C contenant soit un dérivé de protéine à l'anatoxine diphtérique (Meningitec ${ }^{\mathrm{MC}}$, Wyeth et Menjugate ${ }^{\mathrm{MC}}$, Novartis Vaccines) ou à l'anatoxine tétanique (Neis Vac-C ${ }^{\mathrm{MC}}$, GlaxoSmithKline) comme porteur CRM197. Bien que la réponse immunitaire de Menactra ${ }^{\mathrm{MC}}$ ait été comparée à la réponse du vaccin polysaccharidique et ait été jugée non inférieure pour le sérogroupe C, il a été établi que le vaccin polysaccharidique fournit un faible niveau de protection de courte durée contre ce sérogroupe chez les enfants (De Wals et coll., 2005). Une étude cas-témoin visant à évaluer l'efficacité est en cours aux É.-U. (CDC, communication personnelle, 2007). Pour ces raisons, tant que les résultats de ces nouvelles études ne seront disponibles, les trois vaccins conjugués monovalents contre le sérogroupe $C$ présentement approuvés au Canada devraient être préférés pour toutes les indications de vaccination contre la MI du sérogroupe $C$, surtout chez les enfants.

Alors que l'efficacité du vaccin polysaccharidiques dans la prévention de la MI des sérogroupes A et C a été démontrée dans les études expérimentales et d'observation chez les adolescents et les adultes (Frasch 1995; De Wals et coll., 2005), les études immunologiques ont montré que Men4-DT est un vaccin plus puissant. Pour cette raison, Men4-DT pourrait être considéré pour l'immunisation systématique des adolescents, tel que recommandé aux É.-U. (ACIP 2005), y compris ceux déjà immunisés en bas âge d'un vaccin conjugué monovalent contre le sérogroupe $C$ ou d'un vaccin polysaccharidique. Cette injection de rappel vise à assurer que des anticorps en circulation sont présents lorsque les adolescents parviennent aux années de pointe de la MI après la petite enfance, soit entre les âges de 15 et 25 ans. Attendu que la période d'incubation de la MI est courte [entre 2 et 10 jours et le plus souvent entre 3 et 4 jours (Heyman, 2004)] on reconnaît maintenant que les anticorps en circulation sont nécessaires à la prévention de la MI et que la capacité de la réponse anamnestique ne suffit pas à protéger contre la maladie (Auckland et coll., 2006; Snape et coll., 2006). De plus, la fréquence du portage du méningocoque atteint son sommet durant l'adolescence (Cartwright, 1995), et la prévention du portage chez les adolescents pourrait avoir un impact sur l'immunité collective (Trotter et coll., 2005), ce qui protégerait indirectement les nourrissons.

\section{Innocuité}

On associe généralement les vaccins contenant des protéines à des réactions locales légèrement plus communes et sévères que celles des vaccins polysaccharidiques et Men4-DT n'est pas une exception. Cependant, l'expérience de l'administration de Men4-DT dans neuf essais cliniques portant sur plus de 10000 sujets est très rassurante et les événements négatifs observés n'étaient pas très différents de ceux signalés dans les groupes témoins auquel un vaccin polysaccharidique quadrivalent a été administré (Sanofi Pasteur ltée, 2006).

Aux É.-U., Menactra ${ }^{\mathrm{MC}}$ est utilisé à grande échelle pour la vaccination des adolescents et des étudiants des collèges. Une grappe de cas du syndrome de Guillain-Barré (SGB) a été déclarée dans la période de 6 semaines qui a suivi l'administration du vaccin (Woo et coll., 2006). Jusqu'à maintenant, 19 cas de SGB ont été documentés, surtout chez les adolescents et les jeunes adultes. Un risque statistiquement 
négligeable d'environ un cas par million de doses a été calculé (CCNI, 2007). Le SGB est une neuropathie démyélinisante inflammatoire autoimmunitaire aiguë affectant les nerfs moteurs périphériques et/ou sensoriels. On ne comprend pas encore très bien les mécanismes qui en sont la cause (Hahn, 1998; Hughes et coll., 2005). En 1976-1977, on a constaté un risque excessif du SGB par suite de l'administration de vaccins inactivés contre l'influenza porcine (Langmuir et coll., 1984). Cependant, cette association n'a pas été observée ou n'a eu qu'une importance marginale par rapport aux préparations de vaccins contre l'influenza porcine (Hurwitz et coll., 1981; Kaplan et coll., 1982; Lasky et coll. 1998; Roscelli et coll., 1991; Haber et coll., 2004). Lors d'une étude de grande envergure au R.-U. portant sur l'incidence du SGB après l'administration systématique de vaccins à tous les groupes d'âges, aucune association n'a été observée (Hughes et coll., 2006). Au R.-U., plus de 18 millions de doses de trois vaccins antiméningococciques du sérogroupe $C$ ont été administrées au cours de la campagne d'immunisation massive de 1999-2001 et aucune nouvelle grappe de cas de SGB n'a été signalée par le système de surveillance passive des événements contraires (Committee on Safety of Medicines Expert Working Group, 2002). Dans la province de Québec, une étude a été menée afin d'évaluer le risque de SGB après l'adminsitration d'un vaccin conjugué antiméningococcique CRM197 contre le sérogroupe $C$ dans le cadre d'une campagne de vaccination massive en 2001. Les dossiers d'immunisation furent mis en corrélation avec les sommaires de congés d'hôpital et les dossiers médicaux furent examinés. Dans la cohorte de 1,9 million d'individus, la fréquence du SGB durant la période post-vaccination était inférieure aux attentes pour toutes les comparaisons (De Wals P, Deceuninck G, Buucher RM, Ouakki M. Risk of Guillain-Barré syndrome following serogroup $C$ meningococcal conjugate vaccine in Quebec, Canada. Clin Infect Dis, $2008 \mathrm{Apr}$ 15;46(8):e75-7). Une association entre les vaccins conjugués contre le sérogroupe C et le SGB peut raisonnablement être exclue et une association causale entre Men4-DT et le SGB ne peut être établie. Aux É.-U., une mise en garde a été émise pour les personnes ayant des antécédents de SGB, mais la recommandation de vacciner les groupes à risques élevés n'a pas été modifiée (Woo et coll., 2006).

Le CCNI a étudié les données sur l'innocuité de Menactra $^{\mathrm{MC}}$ (CCDR, ...2009). La principale préoccupation touche l'incidence du syndrome de Guillain-Barré (SGB) après l'immunisation. Les Centers for Disease Control (CDC) des États-Unis ont aussi étudié l'innocuité de Menactra ${ }^{\mathrm{MC}}$. « Les CDC sont incapables de déterminer si Menactra ${ }^{\mathrm{MC}}$ augmente un risque de SGB chez les personnes qui reçoivent le vaccin. Le SGB est une maladie rare et les taux attendus de SGB dans la population ne sont pas connus avec précision. Un risque connu constant de sérieuse méningococcie existe. Par conséquent, les CDC recommandent la poursuite des présentes stratégies de vaccination. » (http://www.cdc.gov/ vaccinesafety/concerns/gbsfactsheet.htm).

\section{Administration concomitante du vaccin}

Idéalement, les nouveaux vaccins inclus dans les programmes subventionnés par l'État devraient être administrés en même temps que les autres vaccins afin d'augmenter le niveau de couverture et de minimiser les coûts d'administration. Lutilisation concomitante de Men4-DT avec la formulation pour adulte du vaccin tétanos-diphtérie (dT) a été évaluée et aucune interaction négative significative n'a été observée (Sanofi Pasteur ltée, 2006). Il s'agissait de la plus importante association à étudier à cause de la présence d'anatoxine diphtérique dans les deux produits. Il n'existe présentement aucunes données sur l'administration concomitante de Men4-DT avec d'autres vaccins présentement offerts aux adolescents au Canada, y compris DCaT, l'hépatite A et B et le papillomavirus. 


\section{Stratégies d'immunisation}

Les programmes de vaccination contre la MI devraient avoir les buts suivants : i) prévenir l'occurrence d'éclosions ou d'épidémies, ii) contrôler les éclosions ou épidémies qui n'ont pu être évitées, iii) prévenir les cas sporadiques et iv) prévenir les cas secondaires chez les personnes en contact étroit avec les cas de MI.

Tel que présenté au tableau 1, la vaccination contre les infections méningococciques du sérogroupe $C$ est incluse dans les calendriers d'immunisation de toutes les provinces et tous les territoires canadiens. Pour l'immunisation primaire, la recommandation la plus fréquente est l'administration d'une simple dose de vaccin conjugué contre le type C (C-CMV) à 12 mois (en vigueur au Nouveau-Brunswick, à Terre-Neuve-Labrador, en Nouvelle-Écosse, à
l'Île-du-Prince-Édouard, au Québec, en Ontario, en Saskatchewan et au Nunavut). Limmunisation primaire avec trois doses précoces (2, 4 et 6 mois) a été recommandée en Alberta, mais ce calendrier a été modifié récemment en faveur de l'administration de la troisième dose à 12 mois. Un calendrier de deux doses est en place en ColombieBritannique (2 et 12 mois), au Yukon ( 2 et 6 mois) et dans les Territoires du Nord-Ouest ( 2 et 4 mois). Enfin, une seule dose à 12 mois avec vaccination de rattrapage en $4^{e}$ année du primaire est en vigueur au Manitoba. Cette stratégie est justifiée par la situation épidémiologique de 2004. La vaccination de rattrapage avec calendriers variables existe dans la plupart des juridictions. En Alberta et au Québec, les campagnes d'immunisation massive rendent superflues toute vaccination de rattrapage.

Tableau 1 : Recommandations concernant le calendrier d'immunisation contre la méningococcie invasive du sérogroupe C dans les provinces et territoires canadiens (ASPC 2007/12/28)

\begin{tabular}{|l|l|l|}
\hline \multicolumn{2}{|l|}{ Immunisation primaire } & \multicolumn{1}{|c|}{ Rattrapage (1 dose)* } \\
\hline Provinces & $\begin{array}{l}3 \text { doses : } \\
2,4 \text { et } 12 \text { mois }\end{array}$ & $\begin{array}{l}\text { Une campagne de vaccination massive a été menée en } \\
\text { 2000-2002, ciblant la population des 2-24 ans, et les } \\
\text { vaccins polysaccharidiques méningococciques ont été } \\
\text { utilisés. Par la suite, les vaccins conjugués contre le } \\
\text { sérogroupe C ont été utilisés pour les moins de } 2 \text { ans. }\end{array}$ \\
\hline Alberta & 2 doses : & 1 dose en $6^{e}$ année \\
\hline $\begin{array}{l}\text { Colombie- } \\
\text { Britannique }\end{array}$ & 1 dose à 12 mois & 1 dose en $4^{e}$ année \\
\hline Manitoba & 1 dose à 12 mois & $9^{e}$ année (Menactra) \\
\hline Nouveau-Brunswick & 1 dose à 12 mois & $4^{e}$ année et $9^{e}$ année \\
\hline Terre-Neuve et & 1 dose à 12 mois & $7^{e}$ année et entre 14 et 16 ans \\
\hline Labrador & 1 dose à 12 mois & $7^{e}$ année et entre 15 et 19 ans \\
\hline Ontario & &
\end{tabular}




\begin{tabular}{|c|c|c|}
\hline & Immunisation primaire & Rattrapage (1 dose)* \\
\hline $\begin{array}{l}\text { Île-du-Prince- } \\
\text { Édouard }\end{array}$ & 1 dose à 12 mois & $9^{e}$ année (Menactra) \\
\hline Québec & 1 dose à 12 mois & $\begin{array}{l}\text { Une campagne de vaccination massive a été menée } \\
\text { en } 2001 \text {, ciblant la population des } 2-20 \text { ans, util- } \\
\text { isant principalement un vaccin conjugué de type C. }\end{array}$ \\
\hline Saskatchewan & 1 dose à 12 mois & Entre 4 et $6,6^{e}$ année \\
\hline \multicolumn{3}{|l|}{ Territoires } \\
\hline $\begin{array}{l}\text { Territoires du } \\
\text { Nord-Ouest }\end{array}$ & 1 dose à 12 mois & $\begin{array}{l}\text { Une campagne de vaccination massive a été menée en } \\
2004 \text {, ciblant tous les individus d'âge scolaire avec un } \\
\text { vaccin conjugué de type C. Rattrapage jusqu'à } 5 \text { ans. } \\
\text { Dépistage et rattrapage en } 9^{e} \text { année }\end{array}$ \\
\hline Nunavut & 1 dose à 12 mois & Entre 14 et 16 ans \\
\hline Yukon & $\begin{array}{l}2 \text { doses: } \\
2 \text { et } 6 \text { mois }\end{array}$ & $\begin{array}{l}\text { Rattrapage en } 9^{e} \text { année; étudiants post secondaires } \\
\text { quittant l'école et/ou non vaccinés. }\end{array}$ \\
\hline
\end{tabular}

* Un vaccin conjugué monovalent contre le sérogroupe C est utilisé pour le rattrapage, sauf à l'île-du-Prince-Édouard et au Nouveau-Brunswick où on utilise Men4-DT.

Lutilisation de Men4-DT n'a pas été autorisée pour les moins de 2 ans et, dans ce groupe d'âges, la réponse immunitaire est faible, notamment pour les antigènes C, Y et W135 (Rennels et coll., 2002). Au Canada, la première augmentation de l'infection méningococcique survient vers l'âge d'un an et est causée principalement par le sérogroupe C (figure 1). De plus, aucune province ou aucun territoire n'applique une vaccination systématique à 2 ou 3 ans. Pour toutes ces raisons, Men4-DT ne devrait pas être utilisé pour la vaccination primaire contre le sérogroupe $C$ chez les jeunes enfants. La vaccination primaire devrait plutôt utiliser un vaccin conjugué monovalent contre le sérogroupe $C$ prévoyant une dose à 12 mois, ou éventuellement plus tôt avec une ou deux doses et dose de rappel au cours de la deuxième année (De Wals et coll., 2006).

Au Canada, l'indication préférée d'utilisation de Men4-DT consiste à vacciner les adolescents à l'âge de 12 ans, soit juste avant l'augmentation de l'incidence de la MI qui survient à 13 ans. Pour les adolescents qui n'ont pas été vaccinés auparavant, il s'agirait d'une vaccination primaire. Pour ceux qui ont déjà été vaccinés au C-MCV en bas âge, il s'agirait d'une dose de rappel contre le sérogroupe $C$ et d'une vaccination primaire contre les sérogroupes $\mathrm{A}, \mathrm{Y}$ et $\mathrm{W} 135$. Les résultats des études épidémiologiques au Royaume-Uni et en Espagne indiquent que la baisse progressive de la protection durant les années qui suivent la vaccination primaire d'un vaccin conjugué contre le sérogroupe $C$ est plus prononcée si la vaccination primaire a eu lieu en bas âge (Trotter et coll., 2004; Larrauri et coll., 2005). La modélisation de l'efficacité relative des divers calendriers de vaccination semble indiquer que la revaccination vers l'âge de 12 ans est utile quand la baisse de la protection assurée par une vaccination primaire en bas âge est égale ou supérieure à $3 \%$ par année (De 
Wals et coll., 2006). Pour la protection contre le sérogroupe C, l'ajout d'une revaccination environ 10 ans après la vaccination primaire pourrait prolonger la durée de la protection. D'ailleurs, les concentrations observées d'anticorps bactéricides contre le sérogroupe $\mathrm{C}$ sont 35 fois plus grandes un mois après la revaccination avec Men4-DT qu'après la vaccination primaire (Pichichero et coll., 2005; El Bashir et coll., 2006).

Tout comme le vaccin conjugué contre le sérogroupe C, Men4-DT déclenche probablement l'apparition d'anticorps des muqueuses (Zhang et coll., 2000; Zhang et coll., 2002). Par conséquent, la vaccination d'une importante proportion d'adolescents pourrait réduire sensiblement la transmission des souches pathogènes dans toute la population puisque la prévalence du portage de N. meningitidis est à son maximum dans ce groupe d'âges (Cartwright, 1995). Au Royaume-Uni, à la suite de la campagne d'immunisation massive au moyen de C-MCV (atteignant 81 \% de la population âgée de 18 ans et moins), le portage observé du sérogroupe $\mathrm{C}$ a été réduit de 4,5 $\%$ à $1,5 \%$ chez les étudiants de 15 à 17 ans (Maiden et coll., 2002), alors que l'incidence de la MI du sérogroupe C a diminué de $52 \%$ dans la partie non vaccinée de la population cible (Ramsay et coll., 2003). Il n'existe aucunes données épidémiologiques concernant l'immunité collective induite par un programme de vaccination systématique lorsque seulement une ou deux cohortes sont vaccinées à chaque année. Trotter et ses collègues (2005) ont élaboré un modèle de simulation dynamique de l'infection méningococcique et de la méningococcie. Ce modèle prédit l'effet indirect maximal quand des adolescents sont immunisés par un vaccin antiméningococcique conjugué. Cet effet d'immunité collective pourrait être passablement important après une revaccination contre le sérogroupe $C$ et pourrait empêcher de nouvelles éclosions. En ce qui a trait aux autres sérogroupes, l'immunité collective serait induite par la vaccination des adolescents au Men4-DT, mais un groupe de sujets sensibles persisterait chez les enfants et les adultes plus âgés.

Advenant l'autorisation d'administrer aux enfants de moins de 2 ans un vaccin conjugué quadrivalent antiméningocoque qui démontrent une réaction immunitaire non inférieure au vaccin polysaccharidique contre le sérogroupe $\mathrm{C}$ comparativement aux vaccins monovalents contre le sérogroupe $C$ présentement disponibles, la stratégie idéale serait de faire la transition vers l'utilisation exclusive du produit quadrivalent tant pour la vaccination primaire (utilisant soit une dose à 12 mois, soit une ou deux doses avant un an avec injection de rappel au cours de la deuxième année) que pour l'injection de rappel chez les adolescents (idéalement à 12 ans). 


\section{Coût-efficacité}

Les cas de MI ne sont pas fréquents au Canada, mais sont associés à des coûts sociétaux importants et la perte d'années de vie en bonne santé (De Wals et coll., 2007). Les coûts médicaux moyens à court terme par cas de MI ont été estimés à 13000 \$, les coûts de traitement annuels pour un survivant avec séquelles physiques permanentes à 17000 \$ à moins de 18 ans, et à $4000 \$$ à 18 ans et plus (De Wals et coll., 2007). Il faut également tenir compte des coûts indirects liés aux pertes de productivité causées par la mort prématurée ou les séquelles physiques permanentes.

Les nouveaux vaccins présentent un désavantage par rapport aux anciens produits, dont les coûts de développement ont déjà été payés. Plus particulièrement, les vaccins conjugués multivalents sont plus complexes à produire que les produits univalents. De plus, la capacité de production de Men4-DT est limitée, alors qu'il existe trois installations de fabrication pour les produits univalents du sérogroupe C. Pour les programmes d'immunisation financés par les fonds publics, les provinces et territoires invitent les fabricants de vaccins à soumettre des propositions (habituellement pour des contrats à court terme), et la compagnie offrant le meilleur prix est sélectionnée. Ce processus d'achat entraîne des prix très bas dans un marché où la concurrence est forte, comme on l'a constaté avec MenC-C, dont le coût a rapidement diminué, de 50 \$ à moins de 20 \$. Le prix du marché prévu de Men4-DT pour le secteur public au Canada est de 70 \$ par dose (De Wals et coll., 2007). Dans le futur, cependant, le prix différentiel entre les vaccins $C$ univalents et conjugués quadrivalents pourra diminuer, notamment lorsque plusieurs produits quadrivalents arriveront sur le marché.

Les coûts associés à ces programmes de vaccination potentiels peuvent comprendre l'achat et l'administration des vaccins. Dans une récente analyse coût-efficacité, les coûts d'opportunité marginaux pour l'administration du vaccin Men4-DT à un adolescent avec un autre vaccin recommandé étaient estimés à 8,50 \$ (De Wals et coll., 2007). En employant cette valeur et un prix d'achat du vaccin de 70 \$ par dose, les coûts des programmes pour les gouvernements provinciaux selon différents niveaux de couverture vaccinale des adolescents apparaissent au Tableau 2. Dans l'ensemble, les coûts des programmes varieraient entre 19 et 29 millions \$. Les coûts liés à l'administration du vaccin dans les territoires canadiens seront peut-être plus élevés que dans les provinces plus populeuses, mais il n'existe pas de données probantes permettant d'estimer de manière fiable les coûts totaux des programmes dans ces régions. Les effets indésirables associés à l'administration des vaccins méningococciques conjugués aux adolescents nécessitant des soins médicaux sont rares, et les coûts associés n'affectent pas les coûts totaux des programmes de façon significative (De Wals et coll., 2007).

Tableau 2 : Coût* estimé des programmes pour le système de santé, selon différentes couvertures des populations d'adolescents avec un vaccin méningococcique conjugué quadrivalent au Canada

\begin{tabular}{|c|c|c|c|c|c|}
\hline \multirow{2}{*}{ Province } & \multirow{2}{*}{$\begin{array}{c}\text { Population } \\
\text { (estim. 2006) }\end{array}$} & \multicolumn{4}{|c|}{ Couverture vaccinale } \\
\cline { 3 - 6 } & & $\mathbf{6 0 \%}$ & $\mathbf{7 0 \%}$ & $\mathbf{8 0} \%$ & $\mathbf{9 0} \%$ \\
\hline Terre-Neuve-et-Labrador & 6000 & $283 \$$ & $330 \$$ & $377 \$$ & $424 \$$ \\
\hline Île-du- Prince-Édouard & 2000 & $94 \$$ & $110 \$$ & $126 \$$ & $141 \$$ \\
\hline
\end{tabular}

Conseil pour considération du vaccin conjugé quadrivalent contre le méningocoque ( $A, C, Y, W 135)$ pour utilisation par les provinces et territoire 


\begin{tabular}{|c|c|c|c|c|c|}
\hline \multirow{2}{*}{ Province } & \multirow{2}{*}{$\begin{array}{l}\text { Population } \\
\text { (estim. 2006) }\end{array}$} & \multicolumn{4}{|c|}{ Couverture vaccinale } \\
\hline & & $60 \%$ & $70 \%$ & $80 \%$ & $90 \%$ \\
\hline Nouvelle-Écosse & 11000 & $518 \$$ & $604 \$$ & $691 \$$ & $777 \$$ \\
\hline Nouveau-Brunswick & 9000 & $424 \$$ & $495 \$$ & $565 \$$ & $636 \$$ \\
\hline Québec & 95000 & $4475 \$$ & $5220 \$$ & $5966 \$$ & $6712 \$$ \\
\hline Ontario & 162000 & $7630 \$$ & $8902 \$$ & $10174 \$$ & $11445 \$$ \\
\hline Manitoba & 16000 & $754 \$$ & $879 \$$ & $1005 \$$ & $1130 \$$ \\
\hline Saskatchewan & 14000 & $659 \$$ & $769 \$$ & $879 \$$ & $989 \$$ \\
\hline Alberta & 45000 & $2120 \$$ & $2473 \$$ & $2826 \$$ & $3179 \$$ \\
\hline Colombie-Britannique & 51000 & $2402 \$$ & $2802 \$$ & $3203 \$$ & $3603 \$$ \\
\hline Total des 10 provinces & 411000 & $\$ 19358$ & $\$ 22584$ & $\$ 25811$ & $\$ 29037$ \\
\hline
\end{tabular}

* Les coûts sont indiqués en milliers de dollars canadiens

Présentement, l'option la plus attrayante pour l'utilisation de Men4-DT au Canada serait la vaccination de sujets naifs âgés d'environ 12 ans ou la revaccination de sujets sensibilisés avec un vaccin conjugué univalent du sérogroupe $\mathrm{C}$ (MenC-C) à un jeune âge. On a élaboré un modèle de simulation pour évaluer les effets directs et indirects d'une injection de rappel à 12 ans avec un vaccin méningococcique conjugué univalent $C$ ou quadrivalent ACYW135 dans une cohorte de Canadiens immunisés à l'âge de 12 mois avec MenC-C (De Wals et coll., 2007). Les taux d'incidence et de mortalité propres aux âges et aux sérogroupes ont été dérivés des données de surveillance canadiennes. L'efficacité des vaccins a été estimée à partir de données provenant du R.-U. et de l'Espagne, en présumant qu'ils deviennent moins efficaces à mesure que vieillissent les sujets. Les taux de couverture vaccinale prévus étaient de $90 \%$ à 12 mois et de $70 \%$ à 12 ans. L'immunité collective a été modélisée à partir des données du R.-U. Le coût d'achat des vaccins par dose était de 23 \$ pour MenC-C et 70 \$ pour Men4-DT. Les coûts et les résultats pour la santé ont été actualisés à 3 \% par année. Les résultats, exprimés en dollars canadiens de 2004 et d'un point de vue sociétal, ont été présentés pour un état d'équilibre et une population d'un million de personnes.

Comme on voit dans le Tableau 3, 5,7 cas de méningococcie évitable par la vaccination surviendraient chaque année dans le scénario « sans vaccination ». La vaccination à 12 mois avec MenC-C réduirait de $32 \%$ le fardeau de la maladie. Ajouter MenC-C à 12 ans réduirait de 55 \% le nombre de cas, sans coût marginal (on prévoit une économie mineure). Utiliser Men4-DT pour l'injection de rappel entraînerait une réduction de la maladie de $78 \%$, pour un coût marginal de 31000 $\$$ par AVAQ gagnée, comparativement à une dose de MenC-C à 12 mois. Si l'on compare Men4-DT avec MenC-C comme injection de l'appel, le rapport coût-efficacité différentiel serait de 113000 $\$$ par AVAQ. 
Tableau 3 : Coût-efficacité de différentes stratégies d'immunisation en utilisant le vaccin méningococcique conjugué du sérogroupe $C$ (MenC-C) ou le vaccin méningococcique conjugué quadrivalent (Men4-DT) chez une population d'un million de personnes au Canada, dans un scénario modèle de base (De Wals et coll., 2007).

\begin{tabular}{|c|c|c|c|c|}
\hline Résultat & $\begin{array}{c}\text { Pas de } \\
\text { vaccination }\end{array}$ & $\begin{array}{l}\text { MenC-C à } \\
12 \text { mois }\end{array}$ & $\begin{array}{c}\text { MenC-C à } \\
12 \text { mois et } 12 \text { ans }\end{array}$ & $\begin{array}{l}\text { MenC-C à } 12 \text { mois } \\
\text { et Men4-DT à } 12 \text { ans }\end{array}$ \\
\hline NNombre doses MenC-C & - & 12000 & 21000 & 12000 \\
\hline Nombre doses MenC-4 & - & - & - & 9000 \\
\hline Coûts de programme & - & $316000 \$$ & $604000 \$$ & $1033000 \$$ \\
\hline Cas de MI évités (directs) & - & 1,0 & 1,7 & 2,0 \\
\hline Cas de MI évités (indirects) & - & 0,6 & 2,2 & 2,8 \\
\hline Cas de MI résiduels & 5,7 & 4,1 & 1,8 & 0,9 \\
\hline \multirow[t]{2}{*}{$\begin{array}{l}\text { Coût net différentiel/AVAQ } \\
\text { (intervalle de confiance } \\
95 \% \text { ) }\end{array}$} & - & Réf & $\begin{array}{r}-1000 \$ \\
(-15000 \$ \\
\text { à } 82000 \$)\end{array}$ & $\begin{array}{r}31000 \$ \\
(12000 \$ \\
\text { à } 111000 \$)\end{array}$ \\
\hline & & & Réf & $\begin{array}{c}113000 \$ \\
(72000 \$ \\
\text { à } 198000 \$)\end{array}$ \\
\hline
\end{tabular}

Les résultats des analyses de sensibilité ont montré que l'efficacité des vaccins et le prix différentiel entre les deux vaccins étaient les paramètres ayant le plus grand impact sur les rapports coût/AVAQ. Toute augmentation de l'incidence du sérogroupe Y améliorerait aussi le rapport coût-efficacité marginal associé à Men4-DT. Dans tous les scénarios, toutefois, la revaccination avec MenC-C a été associée à des indices coût-efficacité plus favorables qu'avec Men4-DT, alors que dans la situation épidémiologique actuelle le prix différentiel entre les deux vaccins devrait être considérablement réduit pour renverser cette conclusion.

Différents modèles de simulation de complexité variable ont été élaborés pour analyser l'impact futur de diverses stratégies d'immunisation (Trotter et coll., 2002; De Wals et coll., 2004; Trotter et coll., 2005; De Wals et coll., 2006; De Wals et coll., 2007; Caro et coll., 2007). Ces modèles comportent des limites significatives, dont les plus importantes sont l'épidémiologie imprévisible de Neisseria meningitidis, l'incertitude planant sur l'efficacité à long terme du vaccin méningococcique conjugué et le degré d'immunité collective conférée par la vaccination systématique. Les résultats permettent ainsi de comparer approximativement l'impact relatif de différentes stratégies dans un modèle donné, mais les comparaisons entre les modèles et les indices coût-efficacité absolus doivent être considérés avec grande prudence. 


\section{Acceptabilité des programmes}

La théorie de perception du risque de Slovic (1987) prédit que le niveau d'anxiété et la probabilité que l'on prenne des mesures pour réduire un risque sont plus élevés si la source n'est pas bien connue des personnes exposées ou des experts; si l'exposition est involontaire et difficile à contrôler; et, finalement, si les conséquences sont dévastatrices. La méningococcie invasive possède toutes ces caractéristiques; il n'est donc pas étonnant de la retrouver dans les priorités de prévention au sein de la population. Une étude menée auprès de parents ayant des enfants de moins de sept ans au Canada a révélé que la méningite était la pathologie évitable par la vaccination la plus redoutée (Ipsos Reid, communication personnelle, 2001). Dans la même étude, la possibilité de prévention, les recommandations des professionnels de la santé, ainsi que l'innocuité et l'efficacité du vaccin ont été citées comme les facteurs les plus importants entrant dans la décision de faire vacciner son enfant. L'occurrence d'une éclosion augmente l'anxiété et le besoin d'intervenir, comme on l'a observé au Québec en 1990-1993 et en 2001 (De Wals et coll., 2003). Une étude réalisée en 2002 dans la région de Sherbrooke, Québec, a montré qu'une grande majorité des personnes interrogées approuvaient la campagne d'immunisation systématique qui venait de s'achever, alors que près de $80 \%$ appuyaient l'inclusion du vaccin méningococcique dans le calendrier régulier de vaccination (De Wals et coll., 2002). On peut donc logiquement prédire que l'inclusion d'un vaccin sûr et efficace contre la méningococcie invasive dans le calendrier régulier de vaccination des adolescents au Canada serait bien accueillie par la majorité de la population et des professionnels de la santé. L'expérience a démontré que les groupes opposés à la vaccination sont moins actifs lorsqu'il existe un consensus social et une absence de controverse sur un vaccin donné.
Il est important d'être proactif et de faire circuler des informations objectives sur l'occurrence d'une grappe de cas du syndrome de GuillainBarré suivant l'administration de Menactra ${ }^{\mathrm{MC}}$. On peut faire l'analogie avec le vaccin inactivé contre l'influenza. En 2004, une étude de l'Institute of Medicine révélait que les données sur la relation entre les vaccins contre l'influenza autres que le vaccin contre l'influenza porcine n'étaient pas concluantes (Stratton et coll., 2004). L'information sur ce risque potentiel de très faible magnitude, le cas échéant, est incluse dans les monographies données aux sujets vaccinés (MSSS, 2004). Mais une étude menée dans la région de Sherbrooke en 2000 a montré qu'aucun des répondants, dont 59 $\%$ avaient été vaccinés, n'avait cité le SGB comme un des effets secondaires possibles du vaccin contre l'influenza, ce qui donne à penser que l'information n'a pas été transmise oralement (De Wals, 2000). Durant les entrevues, il fut relativement facile de décrire le syndrome et son risque de mortalité (environ $10 \%$ ). En revanche, il fut beaucoup plus difficile d'expliquer l'indice $10000: 1$ qui existe entre le risque de mortalité annuel lié à l'influenza si l'on n'est pas vacciné (environ 1/1 000) et le risque de mortalité du SGB après avoir été vacciné contre l'influenza (environ 1/10 000 000). Quant à savoir si l'information communiquée sur le risque de contracter le SGB pourrait influencer leur désir d'être vacciné l'année suivante, 89 \% des répondants ont répondu non, $7 \%$ ont répondu oui et $4 \%$ ne savaient pas. Parmi ceux qui n'avaient pas été vaccinés, le seul fait d'être informés de l'existence d'un tel risque renforcerait leur décision de ne pas être vaccinés dans $35 \%$ des cas. Les personnes de 65 ans et plus peuvent accepter davantage un certain risque associé à un vaccin efficace, mais la réaction des adolescents et de leurs parents peut être complètement différente. Tout en informant les sujets vaccinés au Menactra ${ }^{\mathrm{MC}}$, il serait important d'établir l'équilibre entre le devoir 
d'obtenir un consentement éclairé avec le danger de soulever des inquiétudes non fondées et l'absence d'une intervention préventive efficace.

Les injections multiples peuvent être problématiques pour tous les groupes d'âge. Pour réduire au minimum ces impacts potentiels, il est important de planifier le calendrier de vaccination des adolescents de façon à ne pas devoir administrer plus de trois injections par visite. La récente introduction de plusieurs nouveaux vaccins au Canada a considérablement augmenté la charge de travail des vaccinateurs. Pour éviter l'insatisfaction du personnel suivant l'annonce d'un nouveau programme, il est essentiel de préparer le terrain longtemps à l'avance et de fournir les ressources adéquates aux personnes et aux organisations impliquées pour les aider à accomplir cette tâche. Si toutes ces conditions sont réunies, on peut s'attendre à ce que les taux de couverture soient élevés au sein de la population cible, comme c'est le cas dans la majorité des programmes de vaccination publique au Canada (Santé Canada, 1997). 


\section{Faisabilité des programmes}

Idéalement, la vaccination contre la MI ciblant les adolescents devrait être effectuée entre 11 et 13 ans, avant que les changements à leur style de vie ne causent une augmentation des taux d'hébergement asymptomatique de N. meningitidis, qui culminent entre 15 et 20 ans (Cartwright, 1995). Le risque de maladie invasive augmente également à partir de 13 ans, devenant le plus élevé à 18 ans (Figure 1). Ladministration de Men4-DT à l'âge de 9 ou 10 ans risquerait d'offrir une protection sous-optimale durant la période à haut risque qui dure jusqu'à l'âge de 24 ans. Néanmoins, la vaccination des élèves de neuvième année (ayant presque 14 ans), bien qu'elle soit un peu trop tardive, demeure une alternative acceptable. La couverture prévue du groupe d'âge cible est un autre facteur à considérer pour choisir la meilleure stratégie.

Toutes les provinces et territoires canadiens ont des programmes de vaccination pour les jeunes appartenant à ces catégories (Tableau 4). Jusqu'à maintenant, la priorité s'est portée sur l'immunisation des enfants en bas âge. La multiplication des vaccins disponibles pour les adolescents demande que l'on prépare plus soigneusement le calendrier de vaccination pour ce groupe d'âge. Il faut revoir le nombre et le moment des injections de rappel pour la diphtérie, le tétanos et la coqueluche. Un programme scolaire ciblant les étudiants de 12 ans en première année du secondaire présenterait certainement des avantages en ce qui touche la prévalence des sujets naifs, la réponse immunitaire, la présence à l'école, l'obtention du consentement parental et l'acceptabilité de la vaccination, par rapport à un programme ciblant les étudiants de 14 ans et plus. Une étude quasi-expérimentale réalisée au Québec a permis de constater qu'un programme de vaccination scolaire constitue la méthode la plus efficace et la moins coûteuse pour atteindre ce groupe d'âge (Guay et coll., 2003). On peut naturellement s'attendre à ce qu'il soit difficile pour des parents d'amener leur enfant de 10 à 14 ans chez le médecin ou dans un centre de santé pour y être vacciné.

Il est donc nécessaire d'optimiser les vaccinations de ce groupe d'âge, en tenant compte des contraintes particulières et des programmes existants dans chaque juridiction. Limmunisation contre la méningococcie (1 dose), la diphtérie, le tétanos et la coqueluche (1 dose), les hépatites A et B (possiblement 2 doses) et le VPH (1 à 3 doses) pourrait être complétée en deux ou trois sessions concentrées dans la même année.

Tableau 4 : Programmes de vaccination pour les jeunes de 9 à 16 ans dans les provinces et territoires canadiens (ASPC 2007b).

\begin{tabular}{|l|c|l|}
\hline \multicolumn{2}{|c|}{ Hépatite B } & \multicolumn{1}{c|}{ dcaT } \\
\hline Provinces & $5^{\mathrm{e}}$ année (3 doses) & $9^{\mathrm{e}}$ année \\
\hline Alberta & & $9^{\mathrm{e}}$ année \\
\hline Colombie-Britannique & $4^{\mathrm{e}}$ année (3 doses) & $8^{\mathrm{e}}$ ou $9^{\mathrm{e}}$ année \\
\hline Manitoba & & $9^{\mathrm{e}}$ année \\
\hline Nouveau-Brunwwick & & \\
\hline
\end{tabular}




\begin{tabular}{|l|c|l|}
\hline & Hépatite B & \multicolumn{1}{c|}{ dcaT } \\
\hline Terre-Neuve-et-Labrador & $4^{e}$ année (3 doses) & $9^{e}$ année \\
\hline Nouvelle-Écosse & $4^{e}$ année (3 doses) & $9^{e}$ année \\
\hline Ontario & Grade 7 (2 doses) & $14-16$ ans \\
\hline Île-du-Prince-Édouard & & $9^{e}$ année \\
\hline Québec & $4^{e}$ année (3 doses) & $9^{e}$ année (3e secondaire) \\
\hline Saskatchewan & Grade 6 (3 doses) & $8^{e}$ année \\
\hline Territories & \multicolumn{2}{|l}{} \\
\hline Territoires du Nord-Ouest & $9^{e}$ année \\
\hline Nunavut & $9^{e}$ année \\
\hline Yukon & $9^{e}$ année \\
\hline
\end{tabular}

Enfin, des problèmes d'approvisionnement en vaccins peuvent survenir, en particulier lorsqu'un seul vaccin est autorisé et qu'il est produit à un seul endroit sur une chaîne de fabrication unique. Au début de 2006, les États-Unis ont connu une pénurie de MenactraMC, ce qui a forcé les autorités à rationner le vaccin disponible (CDC 2006). Le fabricant avait fait savoir que la situation serait corrigée rapidement, mais il faut prévoir que ce type d'incident surviendra aussi longtemps qu'un seul vaccin méningococcique conjugué quadrivalent sera autorisé. 


\section{Évaluation des programmes}

Il appartient aux autorités de santé publique d'évaluer les programmes de vaccination nouvellement implantés, alors que des ressources appropriées doivent être consacrées aux systèmes de surveillance et aux études spéciales. Pour Men4-DT, les enjeux les plus importants comprennent la qualité des services d'immunisation, la couverture vaccinale de la population cible et l'incidence globale du programme sur l'épidémiologie de la MI. Dans chaque juridiction, des études doivent être menées régulièrement pour évaluer la qualité de l'information fournie aux consommateurs, le respect de leur liberté de choisir et leur degré de satisfaction pour le service reçu. La couverture vaccinale de la population cible doit être analysée à l'aide de registres d'immunisation sophistiqués ou de systèmes d'information permettant d'identifier l'administration de vaccins particuliers à des sujets particuliers. Les enquêtes par envois postaux ou téléphoniques sont d'autres moyens servant à évaluer la couverture vaccinale, tout en dégageant les facteurs qui gênent et qui favorisent la réception du vaccin. Enfin, il faut surveiller l'impact possible du programme d'immunisation sur l'épidémiologie de la MI. À cette fin, il est important d'associer les données de notification aux données de laboratoire et au compte-rendu sommaire du congé de l'hôpital pour bien vérifier les cas de MI. Idéalement, on doit évaluer l'état d'immunisation dans tous les cas de MI incidents afin de dégager les failles du vaccin et leurs causes possibles. La caractérisation génotypique et phénotypique systématique des souches de N. meningitidis par les laboratoires de référence provinciaux et nationaux est également requise. La commutation de capsule et le remplacement clonal ont pu être décrits suite à l'implantation de nouveaux vaccins (Alonso et coll., 2007), et c'est une menace dont il faut tenir compte en employant Men4-DT. 


\section{Questions de recherche}

Jusqu'à présent, aucun essai n'a été effectué pour établir la comparaison entre la réponse immunologique au composant du sérogroupe C de Men4-DT et les vaccins conjugués univalents du sérogroupe $C$ utilisant d'autres supports protéiques. Dans une étude comparée sur une dose de trois différents vaccins méningococciques conjugués univalents du sérogroupe $C$ administrés à des bambins au R.-U., on a observé une réponse anticorps beaucoup plus vigoureuse avec la préparation anatoxine de polysaccharide-tétanos C di-O-acétylé qu'avec les préparations d'oligosaccharide-CRM $\mathrm{CM}_{197} \mathrm{C}$ O-acétylé (Richmond et coll., 2001). Pour cette raison, un calendrier à deux doses pour le produit utilisant l'anatoxine tétanique comme support protéique a été approuvé pour l'immunisation systématique des enfants en bas âge, plutôt que trois doses pour les produits utilisant le support protéique $\mathrm{CRM}_{197}$ (CCNI, 2005). Il importera de comparer l'immunogénicité relative des différents vaccins méningococciques et calendriers de vaccination, en profitant de la variabilité existante des calendriers de vaccination systématique au Canada. La non-infériorité de la réponse immunitaire des vaccins quadrivalents par rapport aux vaccins conjugués univalents $C$ présentement disponibles devrait être démontrée, en particulier pour les enfants de moins de llans. On devrait en outre analyser le bénéfice marginal d'une, deux ou trois doses pour la primovaccination dans le cadre d'études incluant un suivi de plusieurs années (idéalement jusqu'à l'âge de 12 ans).

Lévaluation de la protection conférée par les vaccins méningococciques pose un défi en situation endémique, alors que la méthode privilégiée est l'étude cas-témoins rétrospective. Cela permet de contrôler les variables confusionnelles, ce qui est très important lorsque l'on atteint des taux d'immunisation élevés, supposant des différences significatives dans les caractéristiques présentées par les sujets vaccinés et non vaccinés (Orenstein et coll., 1988; De Wals et coll., 2005). L'efficacité statistique est le principal problème, alors que l'on devrait songer à mener une étude dans plusieurs provinces et à collaborer à un projet similaire aux États-Unis.

Des études sont présentement en cours afin de déterminer le besoin d'une injection de rappel avec Menactra ${ }^{\mathrm{MC}}$. Les résultats devraient être publiés en 2010. Pour mieux évaluer ce programme en 2010, il faudra progresser dans les secteurs d'activité suivants :

1. Contrôle et surveillance de la maladie;

2. Analyse économique pour évaluer l'avantage de Menactra ${ }^{\mathrm{MC}}$ par rapport à d'autres vaccins méningococciques et selon divers calendriers de vaccination;

3. Immunogénicité et durée de la réponse anticorps de différents vaccins méningococciques et calendriers de vaccination. Par exemple :

- Méningococcique conjugué C (MCC) à l'âge de 12 mois (cohortes P/T immunisées depuis 2001)

- $\quad$ MCC à l'âge de 12 à 14 ans (P/T avec programmes de rattrapage scolaire)

- $\quad$ MCC à 12 mois et injection de rappel avec MCC à l'âge de 12 à 14 ans

- Injection de rappel avec le vaccin méningococcique conjugué quadrivalent à l'âge de 12 à 14 ans aux sujets ayant reçu MCC à 12 mois 
- Vaccin méningococcique conjugué quadrivalent aux sujets naifs du vaccin méningococcique âgés de 12 à 14 ans

4. Comparaison de la réponse immunitaire des vaccins conjugués quadrivalents à celle des vaccins MCC chez les enfants de moins de 11 ans;
5. Évaluation de l'efficacité réelle du vaccin méningococcique, de son incidence sur le portage rhinopharyngé des méningocoques et de son effet indirect sur les taux d'atteinte au sein des populations non vaccinées. 


\section{Autres considérations}

\section{Équité}

On peut considérer comme inéquitable la situation qui prévaut actuellement au Canada, où existent des différences marquées dans les calendriers recommandés pour la vaccination systématique et de rattrapage contre le sérogroupe C. Lintroduction de la vaccination systématique ou de la revaccination des adolescents maximisera la protection, réduira les iniquités et harmonisera les pratiques. Du point de vue de la programmation, l'annonce d'un nouveau programme de vaccination pour adolescents offrant une protection individuelle contre une maladie mortelle, tout en minimisant la possibilité de nouvelles éclosions ou épidémies à l'échelle de la population et ne posant pas de risque inacceptable, serait certainement bien reçue par la population.

\section{Considérations éthiques}

Menactra $^{\mathrm{MC}}$ est un vaccin sûr et efficace. Toutefois, à l'instar d'autres vaccins et médicaments, il n'est pas parfaitement sûr ni parfaitement efficace. La décision d'utiliser un vaccin repose sur l'équilibre relatif entre ses risques et ses avantages. La décision d'introduire ce vaccin devrait suivre une réflexion approfondie sur le risque posé par les sérogroupes A, Y et W-135 d'une province ou d'un territoire, ainsi qu'une analyse coût-avantage pour la prévention de la maladie.

\section{Conseils du CCI sur l'emploi préventif des vaccins antiméningococciques}

Le Comté consultatif national de l'immunisation (CCNI) a publié des recommandations détaillées sur l'emploi des vaccins méningococciques présentement autorisés au Canada (réf. GCI, pp. 279-293 et aussi RMTC, vol. 33, et nov. 2007). De plus, une mise à jour a été publiée récemment dans le RMTC, vol. xx. Ces recommandations sont actualisées à mesure que de nouvelles informations deviennent disponibles.

En se fondant sur l'analyse du $\mathrm{D}^{\mathrm{r}}$ De Wals présentée dans ce document (rapport de septembre 2007 à l'ASPC) et sur l'évaluation scientifique du CCNI, le CCI partage les recommandations du CCNI sur l'emploi des vaccins méningococciques de la manière suivante.

But : Réduire la maladie et les décès attribuables à Neisseria meningitidis (N. meningitidis) du sérogroupe $C$ par la vaccination (Conférence de concertation de 2005). 


\section{Conseil pour l'emploi de vaccins méningococciques dans les programmes de vaccination}

En plus de l'information apparaissant dans ce document et de l'information scientifique et épidémiologique fournie par le CCNI, le CCI et le CCNI présentent conjointement les conseils suivants sur l'emploi des vaccins méningococciques dans les programmes subventionnés par l'État.

\begin{tabular}{|l|l|l|}
\hline \multicolumn{1}{|c|}{ Groupe d'âge } & \multicolumn{1}{|c|}{$\begin{array}{c}\text { Vaccin de choix } \\
\text { à considérer }\end{array}$} & \multicolumn{1}{c|}{ Rappel } \\
\hline Petite enfance & $\begin{array}{l}\text { Méningococcique conjugué C } \\
\text { (MenC-C) }\end{array}$ & $\begin{array}{l}\text { Une injection de rappel pour les } \\
\text { jeunes adolescents est recommandée } \\
\text { avec MenC-C ou Men4-DT. }\end{array}$ \\
\hline $\begin{array}{l}\text { Préadolescent } \geq 5 \text { ans } \\
\text { jusqu'à } \mathbf{1 2} \text { ans }\end{array}$ & $\begin{array}{l}\text { Méningococcique conjugué C } \\
\text { (MenC-C) si non reçu dans la } \\
\text { petite enfance }\end{array}$ & $\begin{array}{l}\text { La décision devra être prise lorsque } \\
\text { plus de données seront disponibles } \\
\text { concernant la durée de la protection. }\end{array}$ \\
\hline Adolescent (12 ans et plus) & MenC-C ou Men4-DT & $\begin{array}{l}\text { Davantage de données sont } \\
\text { nécessaires. }\end{array}$ \\
\hline
\end{tabular}

Pour le moment, un programme de vaccination systématique pour la petite enfance avec

Menactra $^{\mathrm{MC}}$ n'est pas recommandé. On devrait songer à administrer aux adolescents une injection de rappel précoce avec MenC-C ou Men4-DT. Dans les provinces et territoires offrant actuellement des programmes de rattrapage pour les adolescents, la méthode la plus pratique serait de transformer le rattrapage en injections de rappel quand les cohortes de la petite enfance déjà vaccinées atteignent l'adolescence. Les P/T choisiront le produit (MenC-C ou Men4-DT) en se fondant sur l'épidémiologie de A, Y et W-135. Le rapport coût-efficacité de la stratégie d'implantation d'un programme à l'adolescence n'est pas disponible à ce stade-ci. Néanmoins, les provinces et territoires qui n'ont pas de programme de rattrapage voudront peut-être adopter une mesure très simple pour les aider à évaluer ce qu'il en coûterait pour implanter un programme pour adolescents. Employant leurs données épidémiologiques et présumant l'immunité à vie, elles peuvent calculer le nombre de MI évités, par année et par sérogroupe, en utilisant soit le vaccin MenC-C ou le Men4-DT. 


\section{Conclusion}

Il semble que la vaccination des jeunes adolescents avec Men4-DT pourrait contribuer de façon significative à prévenir la méningococcie invasive par les sérogroupes $\mathrm{A}$, C, Y et W135 chez la population canadienne, tant pour les cas sporadiques que pour les éclosions (qui ont été habituellement causées par des souches virulentes du sérogroupe $C$ depuis 20 ans). Un tel programme compléterait la primovaccination à un jeune âge avec le vaccin conjugué univalent du sérogroupe $C$, qui est déjà utilisé dans la plupart des provinces et territoires. Dans l'état actuel des choses, la revaccination des jeunes adolescents avec Men4-DT aurait l'avantage de réduire la mortalité et la morbidité à un coût raisonnable, estimé à 31000 \$ par AVAQ gagnée, comparativement à une dose de MenC-C à 12 mois. Dans l'éventualité d'une éclosion, on utilisera de préférence Menactra ${ }^{\mathrm{MC}}$.

Si un vaccin conjugué quadrivalent pour les enfants en bas âge était autorisé, un calendrier à deux doses, la première à 12 mois et la seconde à 12 ans, constituerait probablement la stratégie la plus économique. Une stratégie plus onéreuse, mais seulement un peu plus efficace, consisterait à employer un programme de trois doses, soit à deux mois, 12 mois et 12 ans. Un calendrier à deux doses à un jeune âge, suivi d'une injection de rappel durant la deuxième année et d'une autre durant l'adolescence, serait probablement la stratégie la plus efficace, mais aussi de loin la plus coûteuse. On devrait faire des études d'immunogénicité pour comparer différents calendriers de nouveaux vaccins méningococciques conjugués quadrivalents.

Idéalement, le vaccin méningococcique en période d'adolescence devrait être administré à l'âge de 12 ans dans le cadre d'un programme scolaire ( $7^{\mathrm{e}}$ année) et combiné à d'autres vaccins (par exemple, dcaT et VPH). Il faut revoir tous les programmes de vaccination pour adolescents au Canada, en plus de réfléchir aux calendriers d'immunisation et aux façons d'administrer les vaccins. La vaccination des adolescents contre la méningococcie devrait être bien accueillie par la population et par les professionnels de la santé, qui doivent faire face à des infections méningococciques invasives fulminantes aux conséquences dramatiques. Du point de vue de la programmation, cette décision devrait recevoir bon accueil, ne pas coûter très cher par rapport à d'autres programmes de santé et ne présenter aucun risque important à la lumière des connaissances actuelles. Ultimement, la décision d'utiliser Men4-DT ou un produit univalent du sérogroupe $C$ est un enjeu relevant des priorités provinciales et territoriales fondé sur l'épidémiologie locale des sérogroupes A, Y et W135. 


\section{References}

ACIP (2005). Prevention and control of meningococcal disease. Recommandations du Advisory Committee on Immunization Practices. MMWR 54 (RR-7) : 1-21.

Agence de la santé publique du Canada (ASPC) (2007). Programmes d'immunisation subventionnés par l'État au Canada - Calendrier d'immunisation systématique des nourrissons et des enfants (incluant les programmes de rappel). Disponible à : http://www.phac-aspc.gc.ca/im/ ptimprog-progimpt/table-1-fra.php

Alonso JM et coll. (2007). Workshop on vaccine pressure and Neisseria meningitidis, Annecy, France, 9-11 mars 2005. Vaccine 25 : 4125-9.

Andrews N, Borrow R, Miller E (2003). Validation of serological correlate of protection for meningococcal $\mathrm{C}$ conjugate vaccine by using efficacy estimates from postlicensure surveillance in England. Clin Diagn Lab Immunol 10 : 780-786.

Ashton FE, Caugant DA (2001). The panmictic nature of Neisseria meningitidis serogroup B during a period of endemic disease in Canada. Can J Microbiol 47 : 283-89.

Auckland C, Gray S, Borrow R et coll. (2006). Clinical and immunologic risk factors for meningococcal $C$ conjugate vaccine failure in the United Kingdom. JID 194: 1745 - 52.

Borrow R, Balmer P, Miller E (2005).

Meningococcal surrogates of protection-serum bactericidal antibody activity. Vaccine 23 : 2222-7.

Caro JJ, Möller J, Getsios D et coll. (2007). Invasive meningococcal disease epidemiology and control measures: a framework for evaluation. BMC Public Health 7 : 130.
Cartwright K (1995). Meningococcal carriage and disease. In. Meningococcal disease. Ed. Cartwright K. Chichester, U.K. : John Wiley \& Sons : 71-114.

CDC (2006). Notice to readers : Improved supply of meningococcal conjugate vaccine, recommendation to resume vaccination of children aged 11-12 years. MMWR 55 (43) : 1177.

Comité consultatif national de l'immunisation (CCNI) (2005). Le point sur les vaccins conjugués contre le méningocoque. RMTC vol. 31 (DCC-3) : 1-4.

Comité consultatif national de l'immunisation (CCNI) (2007). Déclaration sur le vaccin conjugué contre le méningocoque, sérogroupes A, C, Y et W135. RMTC vol 33 (DCC-3): 1-24.

Committee on Safety of Medicines Expert Working Group. (2002). Report of the Committee on Safety of Medicines Expert Working Group on Meningococcal Group C Conjugate Vaccines. London, UK, Department of Health.

De Wals P (2000). L'information sur le risque de contracter le syndrome de Guillain-Barré peutelle modifier l'intention de se faire vacciner contre l'influenza? RMTC 26 : 205-7.

De Wals P (2006). Immunization strategies for the control of serogroup $C$ meningococcal disease in developed countries. Expert Rev Vaccines 5 : 269-75.

De Wals P, Allard MA, Guindon K et coll. (2002). La vaccination contre le méningocoque est-elle utile? Résultats d'une enquête dans la région de Sherbrooke (Québec) RMTC Vol. 28 : 61-63.

De Wals P, Coudeville L, Trottier P et coll. (2007). Vaccinating adolescents against meningococcal 
disease in Canada: a cost-effectiveness analysis. Vaccine $25:$ 5433-40.

De Wals P, Deceuninck G, Boulianne N et coll. (2004). Effectiveness of a mass immunization campaign using serogroup $C$ meningococcal conjugate vaccine. JAMA $292:$ 2491-2494.

De Wals P, Deceuninck G, De Serres G et coll. (2005). Effectiveness of serogroup C meningococcal polysaccharide vaccine: results from a case-control study in Quebec. Clin Infect Dis 40 1116-22.

De Wals P, Duval B, De Serres G et coll. (2003). Santé publique : le contrôle des maladies méningococciques au Québec. Médecine/Sciences 19 : 1011-5.

De Wals P, Nguyen VH, Erickson LJ et coll. (2004). Cost-effectiveness of immunization strategies for the control of serogroup $C$ meningococcal disease. Vaccine 22 : 1233-40.

De Wals P, Trottier P, Pépin J (2006). Relative efficacy of different immunization schedules for the prevention of serogroup $\mathrm{C}$ meningococcal disease: a model-based evaluation. Vaccine 24 3500-4.

Deeks S, Kertesz D, Ryan A et coll. (1997). Surveillance de la méningococcie invasive au Canada, 1995-1996. RMTC vol. 23-16:121-125.

El Bashir H, Heath PT, Papa T et coll. (2006). Antibody responses to meningococcal (groups A, C, Y and W135) polysaccharide diphtheria toxoid conjugate vaccine in children who previously received meningococcal C conjugate vaccine. Vaccine 24 : 2544-2549.

Erickson L, De Wals P (1998). Complications and sequelae of meningococcal disease in Quebec, Canada, 1990-1994. Clin Infect Dis 26:1159-64.
Erickson LJ, De Wals P, Farand L (2005). An analytical framework for immunization program planning in Canada. Vaccine $23: 2468-74$.

Frasch CE (1995). Meningococcal vaccines: past, present and future. Dans : Cartwright K, ed. Meningococcal disease. Chichester: John Wiley and Sons : 245-83.

Girard MP, Preziozi MP, Aguado MT et coll. (2006). A review of vaccine research and development: Meningococcal disease. Vaccine $24:$ 4692-4700.

Goldschneider I, Gotschlich EC, Artenstein MS (1969). Human immunity to the meningococcus. I. The role of humoral antibodies. J Exp Med 129 : 1307-26.

Granoff DM, Harris SL (2004). Protective activity of group $C$ anticapsular antibodies elicited in two-year-olds by an investigational quadrivalent Neisseria meningitidis-diphtheria toxoid conjugate vaccine. Pediatr Infect Dis J 23 : 490-7.

Granoff DM, Morgan A, Welsch JA (2005). Immunogenicity of an investigational quadrivalent Neisseria meningitidis-diphtheria toxoid conjugate vaccine in 2-year old children. Vaccine 23 : 43074314.

Granoff DM, Morgan A, Welsch JA (2005). Persistence of group $C$ anticapsular antibodies two to three years after immunization with an investigational quadrivalent Neisseria meningitidisdiphtheria toxoid conjugate vaccine. Pediatr Infect Dis J 24 : 132-36.

Guay M, Clouâtre AM, Blackburn M et coll. (2003). Effectiveness and cost comparison of two strategies for hepatitis B vaccination of schoolchildren. Can J Public Health 94 : 64-7. 
Haber P, DeStefano F, Angulo FJ et al (2004). Guillain-Barré syndrome following influenza vaccination. JAMA 292 : 2478-81.

Hahn A (1998). Guillain-Barré syndrome. Lancet $352: 635-41$.

Harrison LH, Jolley KA, Shutt KA et coll. (2006). Antigenic shift and increased incidence of meningococcal disease. J Infect Dis 193 : 1266-74.

Hughes RA, Charlton J, Latinovic R et coll. (2006). No association between immunization and Guillain-Barré syndrome in the United Kingdom, 1992 to 2000. Arch Intern Med 166 : 1301-4.

Hughes RA, Cornblath DR (2005). Guillain-Barré syndrome. Lancet 366 : 1653-66.

Hurwitz ES, Schonberger LB, Nelson DB et coll. (1981). Guillain-Barré syndrome and the 19781979 influenza vaccine. N Engl J Med 304 : 1557-61.

Kaplan JE, Katona P, Hurwitz ES et coll. (1982). Guillain-Barré syndrome in the United States, 1979-1980 and 1980-1981. Lack of an association with influenza vaccination. JAMA 248 : 698-700.

Lagos R, Papa T, Mu oz A et coll. (2005). Safety and immunogenicity of a meningococcal (groups A, C, Y, W-135) polysaccharide diphtheria toxoid conjugate vaccine in healthy children aged 2 to 10 years in Chile. Human Vaccines $1: 228-31$.

Langmuir AD, Bregman DJ, Kurland LT et coll. (1984). An epidemiologic and clinical evaluation of Guillain-Barré syndrome reported in association with the administration of swine influenza vaccines. Am J Epidemiol 119 : 841-79.

Larrauri A, Cano R, Garcia M et coll. (2005). Impact and effectiveness of meningococcal C conjugate vaccine following its introduction in Spain. Vaccine 23 : 4097-100.

Lasky T, Terracciano GJ, Magder L et coll. (1998). The Guillain-barré syndrome and the 1992-1993 and 1993-1994 influenza vaccines. N Engl J Med 339 : 1797-1802.

Law DKS, Stoltz J, Henderson AM et al (2005). Antigenic and genetic characterization of serogroup C meningococci isolated from invasive meningococcal disease in Canada from 1999 to 2003. Can J Microbiol 51 : 523-30.

Lorange M, Jetté L (2002). Surveillance des infections envahissantes à Neisseria meningitidis. Rapport annuel 2001. Québec: Institut national de santé publique, Laboratoire de santé publique du Québec. (http://www.inspq.qc.ca/pdf/ publications/113_Neisseria meningitidis2001.pdf)

Maiden MC, Stuart JM for The U.K. Meningococcal Carriage Group (2002). Carriage of serogroup $C$ meningococci 1 year after meningococcal $\mathrm{C}$ conjugate polysaccharide vaccination. Lancet 359: 1829-30.

MSSS (Ministère de la Santé et des Services sociaux) (2004). Protocole d'immunisation du Québec. Québec (QC) : Ministère de la Santé et des Services sociaux.

Orenstein WA, Bernier R, Hinman AR (1988). Assessing vaccine efficacy in the field. Epidemiol Rev 10: 212-241.

Pichichero M, Casey J, Blatter M et coll. (2005). Comparative trial of the safety and immunogenicity of quadrivalent (A, C, Y, W-135) meningococcal polysaccharidediphtheria conjugate vaccine versus quadrivalent polysaccharide vaccine in two-to ten-year-old children. Pediatr Infect Dis J 24 : 57-62. 
Pichichero ME (2005). Meningococcal conjugate vaccines. Expert Opin Biol Ther 5 : 1475-89.

Pollard AJ (2004). Global epidemiology of meningococcal disease and vaccine efficacy. Pediatr Infect Dis J 23 (supplement) : S274-9.

Pollard AJ, Frasch C (2001). Development of natural immunity to Neisseria meningitidis. Vaccine $19: 1327-46$.

Ramsay ME, Andrews NJ, Trotter CL et coll. (2003). Herd immunity from meningococcal serogroup $C$ conjugate vaccination in England: database analysis. BMJ 326:365-6.

Rennels M, King J, Ryall R et al (2002). Dose escalation, safety and immunogenicity study of a tetravalent meningococcal polysaccharide diphtheria conjugate vaccine in toddlers. Pediatr Infect Dis J 21 : 978-979.

Rennels M, King Jr. J, Ryall R et coll. (2004). Dosage escalation, safety and immunogenicity study of four dosages of a tetravalent meningococcal polysaccharide diphtheria toxoid conjugate vaccine in infants. Pediatr Infect Dis J $23: 429-35$.

Richmond P, Borrow R, Goldblatt D et al (2001). Ability of 3 different meningococcal $C$ conjugate vaccines to induce immunologic memory after a single dose in UK toddlers. J Infect Dis 183 : 160-3.

Rivest P, Sagot B, Bédard L (1999). Evaluation of the completeness of reporting of invasive meningococcal disease. Can J Public Health 90 : 250-251.

Roscelli JD, Bass JW, Pang L (1991). Guillain-Barré syndrome and influenza vaccination in the US Army, 1980-1988. Am J Epidemiol 133 : 952-5.
Rosenstein NE, Perkins BA, Stephens DS et coll. (2001). Meningococcal disease. N Engl J Med 344 : 1378-88.

Sanofi Pasteur Limited (2006). Product monograph. Menactra TM. Meningococcal (groups A, C, Y and W-135) polysaccharide diphtheria toxoid conjugate vaccine. Toronto, Ontario.

Santé Canada (1997). Rapport sur l'immunisation au Canada, 1996, RMTC vol 23-S4. Disponible à : http://www.phac-aspc.gc.ca/publicat/ccdr-rmtc/ 97vol23/23s4/index_f.html

Slovic P (1987). Perception of risk. Science 236 : 280-5.

Snape MD, Kelly DF, Salt P et coll. (2006). Serogroup C meningococcal glycoconjugate vaccine in adolescents: Persistance of bactericidal antibodies and kinetics of the immune response to a booster vaccine more than 3 years after immunization. CID 43: 1387-94.

Squires SG, Deeks SL (2004). Surveillance accrue des méningococcies invasives au Canada: du $1^{\text {er }}$ janvier 1999 au 31 décembre 2001. RMTC vol. $30: 17-28$.

Squires SG, Pelletier L, Mungai M et coll. (2000). Les méningococcies invasives au Canada, du $1^{\text {er }}$ janvier 1997 au 31 décembre 1998. RMTC vol. 26-21:177-182.

Statistique Canada (1996). Life tables, Canada and Provinces 1990-1992. Catalogue 84-537 Occasional. Ottawa.

Stein KE (1992). Thymus-independent and thymus-dependent responses to polysaccharide antigens. J Infect Dis 165 (Suppl. 1) : S49-52. 
Stephens DS, Greenwood B, Brandtzaeg P (2007). Epidemic meningitis, meningococcaemia, and Neisseria meningitidis. Lancet 369 : 2196-210.

Stratton K, Alamario DA, Wizemann T et coll. (2004). Immunization safety review : Influenza vaccines and neurological complications. Washington, DC : Institute of Medicine.

Trotter CL, Andrews NJ, Kaczmarski EB et coll. (2004). Effectiveness of meningococcal serogroup $\mathrm{C}$ conjugate vaccine 4 years after introduction. Lancet $364: 365-67$.

Trotter CL, Edmunds WJ (2002). Modelling cost effectiveness of meningococcal serogroup $C$ conjugate vaccination campaign in England and Wales. BMJ $324: 1-6$.

Trotter CL, Gay NJ, Edmunds WJ (2005). Dynamic models of meningococcal carriage, disease, and the impact of serogroup $C$ conjugate vaccination. Am J Epidemiol $162:$ 89-100.

Tsang RS, Henderson AM, Cameron ML et al (2007). Genetic and antigenic analysis of invasive serogroup Y Neisseria meningitidis isolates collected from 1999 to 2003 in Canada. J Clin Microbiol 45 : 1753-8.
Vu DM, Welsch JA, Zuno-Mitchell P et coll. (2006). Antibody persistence 3 years after immunization of adolescents with quadrivalent meningococcal conjugate vaccine. J Infect Dis $193: 821-8$.

Welsh JA, Granoff D (2004). Naturally acquired passive protective activity against Neisseria meningitidis group $C$ in the absence of serum bactericidal activity. Infect. Immun. 72 : 5903-9.

Woo EJ, Ball R, Braun M et coll. (2006). Update : Guillain-Barré syndrome among recipients of Menactra ${ }^{\circledR}$ meningococcal conjugate vaccineUnited States, June 2005-September 2006. MMWR 55 (41) : 1120-4.

Zhang Q, Choo S, Everard J et al (2000). Mucosal immune responses to meningococcal Group C conjugate and Group A and C polysaccharide vaccines in adolescents. Infect Immun $68: 2692-7$.

Zhang Q, Pettitt E, Burkinshaw R et coll. (2002). Mucosal immune responses to meningococcal conjugate polysaccharide vaccines in infants. Pediatr Infect Dis J $21: 209-13$. 